\title{
Variation in occupancy and habitat use of Mobula alfredi at a major aggregation site
}

\author{
L. I. E. Couturier ${ }^{1,2, *}$, P. Newman ${ }^{2,3}$, F. R. A. Jaine ${ }^{2,4,5}$, M. B. Bennett ${ }^{2,6}$, \\ W. N. Venables ${ }^{7}$, E. F. Cagua ${ }^{8}$, K. A. Townsend ${ }^{2,6,9}$, S. J. Weeks ${ }^{2,10}$, \\ A. J. Richardson ${ }^{2,7,11}$
}

${ }^{1}$ Laboratoire des Sciences de l'Environnement Marin (UMR 6539 LEMAR 1, IRD, UBO, CNRS, Ifremer), Institut Universitaire Européen de la Mer, rue Dumont d'Urville, 29280 Plouzané, France

${ }^{2}$ Project Manta, The University of Queensland, St. Lucia, QLD 4072, Australia

${ }^{3}$ Atlas of Living Australia, CSIRO National Collections and Marine Infrastructure, Docklands, Melbourne VIC 3008, Australia ${ }^{4}$ Sydney Institute of Marine Science, 19 Chowder Bay Road, Mosman, NSW 2088, Australia

${ }^{5}$ Department of Biological Sciences, Macquarie University, Sydney, NSW 2109, Australia

${ }^{6}$ School of Biomedical Sciences, The University of Queensland, St. Lucia, QLD 4072, Australia

${ }^{7}$ CSIRO Oceans and Atmosphere, Queensland BioSciences Precinct (QBP), St Lucia, QLD 4072, Australia

${ }^{8}$ Centre for Integrative Ecology, School of Biological Sciences, University of Canterbury, Private Bag 4800, Christchurch 8140, New Zealand

${ }^{9}$ School of Science and Engineering, University of Sunshine Coast, Fraser Coast, QLD 4655, Australia

${ }^{10}$ Biophysical Oceanography Group, School of Geography, Planning and Environmental Management, The University of Queensland, St. Lucia, QLD 4072, Australia

${ }^{11}$ Centre for Applications in Natural Resource Mathematics, The University of Queensland, St. Lucia, QLD 4072, Australia

ABSTRACT: Understanding variations in habitat use through time contributes to identification of habitats critical for species survival. Here we used passive acoustic telemetry to examine the residency and site fidelity patterns of the reef manta ray Mobula alfredi at Lady Elliot Island (LEI), a key aggregation site in eastern Australia. Six acoustic receivers were moored around LEI between 2009 and 2012, and 34 acoustic transmitters were deployed on manta rays. All tagged animals returned to this site within their recording period, with some individuals visiting the area for up to 23 consecutive days. Using a set of mixed effect models, we analysed the hourly visitation patterns of manta rays in relation to temporal and environmental variables. Diel phase and sea temperature showed the strongest effects on the presence of manta rays, with weaker effects detected for wind direction, wind speed and moon illumination. Individuals occupied LEI habitat mostly during daylight hours and in calm weather conditions, which may be linked with behavioural thermoregulation, social interactions and cleaning activities. Their absence at night may be related to foraging strategies in deeper offshore waters. The effect of sea temperature reflects the greater seasonal occurrence of manta rays at LEI in winter, when temperatures are coolest, potentially in response to regional food availability. The high degree of manta ray site fidelity at aggregation sites underscores the importance of these areas as key daytime habitats for the species. We suggest that conservation measures should prioritise the protection of coastal aggregation habitats from overexploitation and degradation.

KEY WORDS: Acoustic telemetry - Site fidelity - Residency - Generalised linear mixed models · Elasmobranch $\cdot$ Conservation 


\section{INTRODUCTION}

Information on how and why individuals access particular sites across various time and space scales contributes to the identification of critical habitats for a species. Better knowledge of the underlying reasons for habitat occupancy and movements can, in turn, underpin the understanding of a species' abundance and distribution, which is of importance for conservation (Venier \& Fahrig 1996, Dulvy et al. 2004). Such knowledge can be used to assess impacts of anthropogenic habitat degradation and fisheries, two of the principal causes of biodiversity loss (Dobson et al. 2006), and can support the application of conservation measures such as marine protected areas (Chapman et al. 2005).

Many elasmobranch species tend to return and occupy certain areas (i.e. show site fidelity), exhibiting site-faithful behaviour to natal, breeding and/or foraging grounds (Hueter et al. 2005). Some coastal elasmobranch species are associated with a particular site year-round (Barnett et al. 2012), whereas others only occupy certain areas seasonally (Dudgeon et al. 2013). Many juvenile sharks have a tendency to remain within nursery grounds for considerable periods of time (Heupel et al. 2007), while adults tend to have large home ranges but return to one or more sites during their lives (DiBattista et al. 2008).

Despite their ability to travel long distances, many large migratory elasmobranchs revisit and aggregate at specific areas over several years (e.g. the whale shark Rhincodon typus, Rowat et al. 2011; the white shark Carchardon carcharias, Jorgensen et al. 2012; and the reef manta ray Mobula alfredi, Couturier et al. 2014). Aggregations have been associated with reproduction, foraging and, in the case of manta rays, the presence of cleaning stations (Couturier et al. 2011). Long-term site fidelity in these species suggests that aggregation sites are key habitats for their populations (Bansemer \& Bennett 2011). Anthropogenic habitat degradation at these aggregation sites could thus have deleterious effects on the population viability of large elasmobranchs (Travis 2003). Targeted fisheries at aggregation sites can deplete local populations (Alava et al. 2002). Unmanaged tourism industries exploiting predictable aggregations can also have a detrimental effect on a population through habitat degradation, but also through disturbance of the normal habitat use and behaviour of individuals (Bruce \& Bradford 2013). Understanding the biotic and abiotic factors that influence the aggregation and site fidelity of a species, and thus the role of its habitat, is needed to assess the poten- tial impact of anthropogenic activities and to implement effective conservation measures.

The reef manta ray is resident to tropical and subtropical waters (Marshall et al. 2009), and forms aggregations regularly at many sites around the world, with adult individuals often displaying strong site affinity (e.g. Deakos et al. 2011, Couturier et al. 2014). The species is listed as Vulnerable on the IUCN Red List of Threatened Species and in CITES Appendix II due to fisheries pressure that is likely to be unsustainable considering its conservative life history (Marshall et al. 2011). However, the ecological understanding of manta rays that is needed to evaluate the importance of their aggregation sites is limited. Aggregations of reef manta rays have been linked to seasonal food availability, the use of cleaning stations and reproductive behaviour (e.g. Deakos et al. 2011, Jaine et al. 2012). In particular, Dewar et al. (2008) showed that reef manta rays were more likely to visit aggregation sites in Indonesia during the day, and during full and new moons when the tidal ranges and currents varied the most. This study also showed that reef manta rays exhibited long-term site fidelity within the Komodo Marine Park, Indonesia, where some protection from local targeted fisheries is provided to the species (Dewar et al. 2008).

Reef manta rays aggregate at several sites along the east coast of Australia (Couturier et al. 2011). The species is not exploited by fisheries in the region and represents an important economic resource for diving and tourism industries (Couturier et al. 2011). Lady Elliot Island (LEI) in the southern Great Barrier Reef is a popular ecotourism location where reef manta rays are found year-round, with a peak in numbers during the austral winter (Couturier et al. 2011, 2014). At this site, reef manta rays are commonly seen at cleaning stations up to approximately $20 \mathrm{~m}$ deep, and swimming or feeding near the surface (Couturier et al. 2011). Couturier et al. (2014) showed that a major part of the sampled reef manta ray population in east Australia were adult individuals that use and return to LEI over multiple years (up to $30 \mathrm{yr}$ ), suggesting an important regional role of this aggregation site for the species. Through the analysis of daily observations from tourism operators on LEI, Jaine et al. (2012) showed that more reef manta rays were observed at this site in autumn and winter, around full and new moons, at low wind speeds, and when there was higher chlorophyll $a$ concentrations. However, these findings were based on boating and diving activities that had relatively short discontinuous observation periods and were restricted to daytime and to areas visible to the 
observer. Passive acoustic telemetry allows for a more comprehensive analysis of visitation patterns as data can be collected continuously and simultaneously at several locations and over long periods of time. Passive acoustic telemetry thus allows us to develop a more complete picture of the habitat use and occupancy of individuals on a continuous $24 \mathrm{~h}$ basis (e.g. during the night when boat-based and diver observations are not possible). A pertinent placement of acoustic receivers around an aggregation site (e.g. around a coral cay island) can provide fine-scale insights on the occupation patterns of reef manta rays within their habitat and how it may relate to individual behaviour. On a large-scale, deploying receivers at several aggregation sites along the coastline can provide information on regional movements and visitation patterns of reef manta rays for each area.

Here we used passive acoustic telemetry to determine (1) residency patterns (i.e. time period spent at site) of individual manta rays at the LEI aggregation site, (2) the site fidelity of individual rays at LEI (individuals returning to LEI), and (3) the influence of environmental variables on the visitation pattern of individuals at LEI, including time-of-day, sea temperature, month, tidal phase, moon illumination, wind speed and direction. Using a generalised linear mixed effect modelling approach, we examined the effect of a set of 7 environmental variables on hourly manta ray visitation patterns over a $3 \mathrm{yr}$ period. Our main research question was to determine whether manta ray occurrence varied between day- and night-time, and was linked with other environmental conditions. We hypothesised that manta rays mostly occur at LEI during daytime and that environmental variables have a similar effect on their diurnal presence as shown by Jaine et al. (2012).

\section{MATERIALS AND METHODS}

\section{Acoustic array}

LEI is the southernmost coral cay of the Great Barrier Reef $\left(24^{\circ} 06^{\prime} \mathrm{S}, 152^{\circ} 42^{\prime} \mathrm{E}\right)$ located approximately $80 \mathrm{~km}$ offshore from the Australian mainland. Six VR2W omni-directional receivers (Vemco) were deployed at accessible dive sites around LEI (Fig. 1a). Five of the receivers were deployed in June 2009 (Spiders Ledge, Severance, Lighthouse Bommie, Sunset Drift and Tubes), and a sixth receiver (Groupers Grovel) was deployed in June 2010 to increase coverage on the eastern side of the reef (Fig. 1a). Each receiver was suspended approximately $2 \mathrm{~m}$ above the seafloor (varying between 14 and $26 \mathrm{~m}$ depth) on a mooring line secured to the seafloor by concrete blocks (Fig. 2c). Receivers were positioned to provide acoustic coverage around the island, with a focus on areas where reef manta rays are commonly sighted, and taking the accessibility of the site into account. Receivers were retrieved by SCUBA divers 3 times a year (February, June and September to October) to download data and were redeployed as soon as possible after being serviced and re-initialised. No receivers were deployed at LEI between February and June 2010. Each receiver automatically logged the presence of acoustic transmitters (or tags) that had been attached to reef manta rays (see 'Tag-

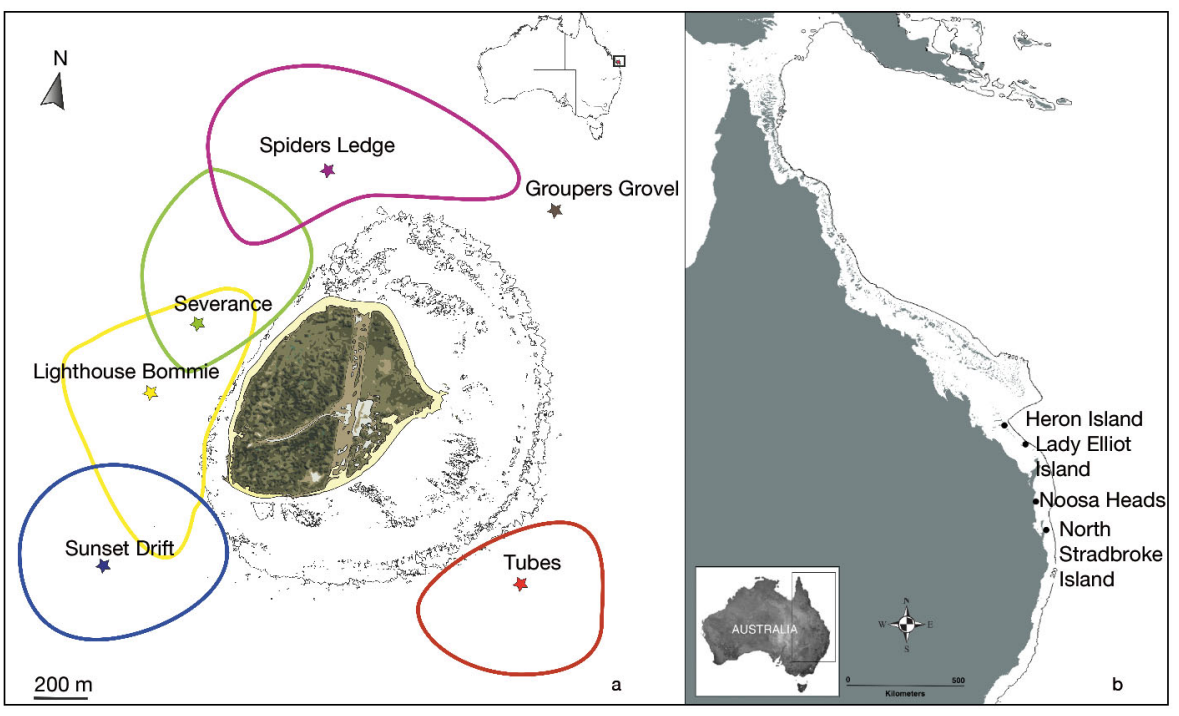

Fig. 1. (a) Lady Elliot Island and its reef with locations of the 6 VR2W receivers and their approximate maximum detection ranges (indicated by coloured lines matching the colour of each receiver); range testing was not performed at Goupers Grovel. (b) Eastern Australia showing locations where tagged reef manta rays Mobula alfredi were detected by VR2W receivers deployed by other researchers from the Australian animal tracking community of the Integrated Marine Ob-serving System 

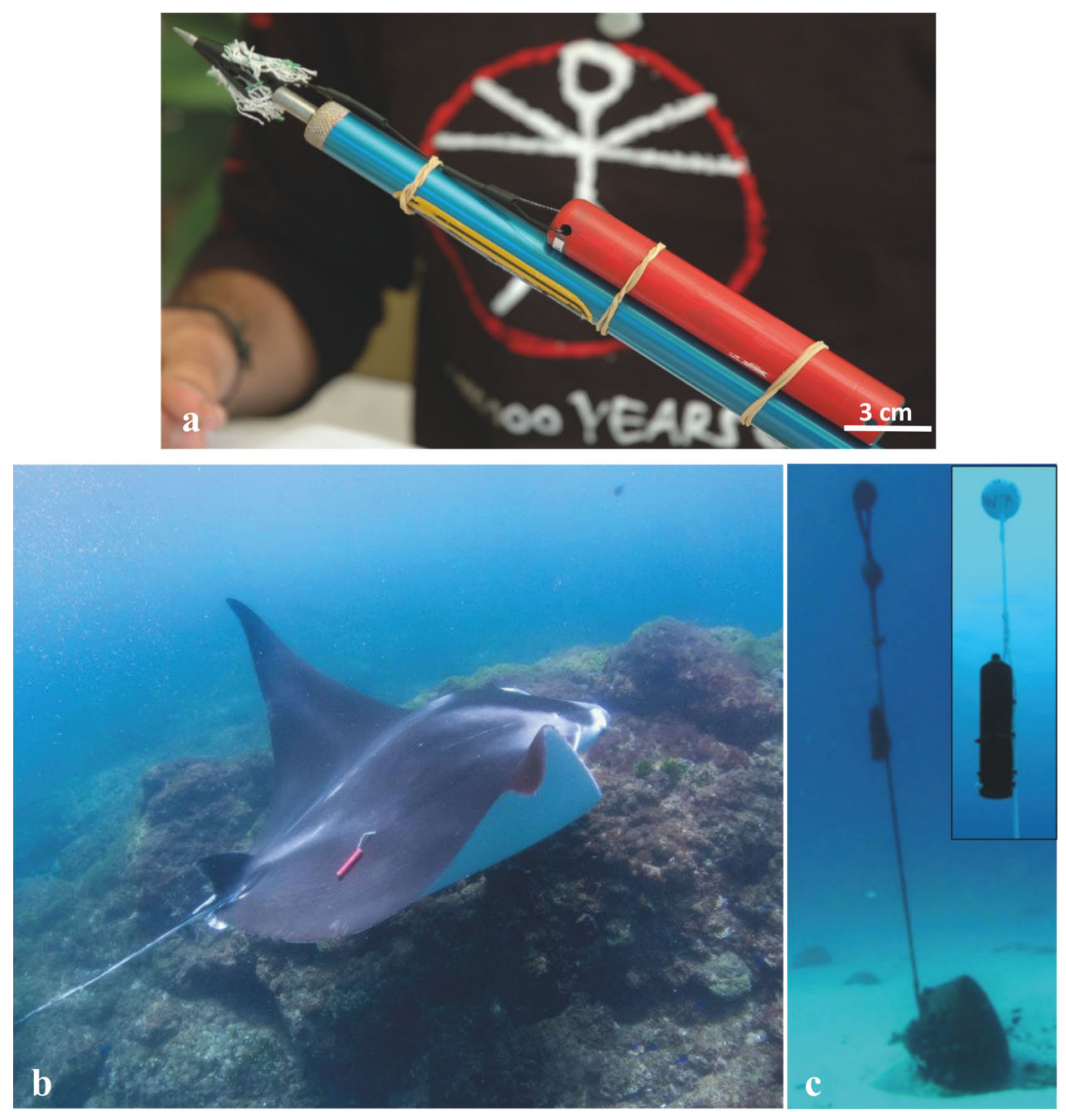

Fig. 2. (a) Example of an acoustic tagging set up (copyright: Kaufmann Productions, used by permission), (b) acoustic tag attached on the dorsal side of a manta ray Mobula alfredi (copyright: Graeme Haas, used by permission), and (c) VR2W receiver deployed underwater at Lady Elliot Island

ging' below), whenever a transmitter was detected within a receiver's range. Acoustic tags attached to reef manta rays were occasionally detected by VR2W acoustic receivers deployed in other sections of the coastline by the Australian animal tracking community of the Integrated Marine Observing System (IMOS, http://imos.org.au) (Fig. 1b). Detections of tagged manta rays on these receivers were accessed via the IMOS Acoustic Tracking Database (https:// animaltracking.aodn.org.au) and identified individuals that had left the study area and still retained their tags (Table 1).

\section{Tagging}

A total of 33 reef manta rays were tagged with V16-6H ( $=12), \mathrm{V} 16-1 \mathrm{H}(\mathrm{n}=3)$ and V16-5H $(\mathrm{n}=19)$ coded transmitters (Vemco) between June 2009 and September 2012 and had various detection periods (Table 1). Tags were externally secured on free- swimming manta rays using an umbrella-shaped plastic dart head attached to the tag by approximately $100 \mathrm{~mm}$ of $320 \mathrm{~kg}$ test Dyneema braided line (Fig. 2a). Using a modified Hawaiian hand-sling, the dart was inserted 2 to $3 \mathrm{~cm}$ into the dorsal musculature of the pectoral fin, near the margin of the body cavity on the posterior part of the fin (Fig. 2b). Most individuals were tagged on the west side of the island during feeding and cleaning activities. Although individuals responded by swimming away immediately after tag insertion, they were usually observed resuming their activities within a few minutes. Each acoustic tag was identified by a unique pulse-train emitted at a frequency of $69 \mathrm{kHz}$. Random delays varying between 70 and $300 \mathrm{~s}$ were used to reduce the likelihood of 'tag collisions'.

The ventral surface of each individual was photographed prior to the tagging to allow for photo-identification and to determine gender (see Couturier et al. 2011 for detailed methodology). Behaviour (i.e. cleaning, courtship or feeding) and approximate disc width of tagged individuals were recorded at the time of tagging.

Tagging was undertaken in June 2009 ( $\mathrm{n}=12$ individuals tagged), March $2010(\mathrm{n}=1)$, June $2010(\mathrm{n}=2)$, February $2011(n=3)$, June $2011(n=10)$ and June 2012 $(n=6)$ (Table 1). One individual was tagged a second time after losing its first transmitter and being at liberty for 188 d (ID 291, Table 1). Retention time of tag was a major issue as 14 of the 34 tags deployed were detected for $<100 \mathrm{~d}$ (Table 1). Material (e.g. tether type) and anchoring technique were adapted over time to maximise retention time. It was not possible to distinguish between acoustic tag loss and emigration from the study area for individuals that were neither photographed nor recorded on any of the receivers from other monitored sites within the IMOS network. For this study, tags were considered lost when no detection was recorded on any of the receivers along the coast (Table 1). Tag loss was confirmed for several tagged individuals that had no transmitter when they were re-sighted and/or photographed (Table 1). Little to no external scarring of the tag insertion wound remained on individuals after tag loss. 
Table 1. Summary of tag deployments on Mobula alfredi at Lady Elliot Island (except for tag ID 64939 that was deployed at North Stradbroke Island). DW: disc width, HI: Heron Island, LEI: Lady Elliot Island, NSI: North Stradbroke Island. Dates are given as $\mathrm{dd} / \mathrm{mm} / \mathrm{yy}$

\begin{tabular}{|c|c|c|c|c|c|c|c|c|c|c|c|c|}
\hline $\begin{array}{l}\text { Tag ID } \\
\text { code }\end{array}$ & $\begin{array}{c}\text { Type of } \\
\text { tag }\end{array}$ & $\begin{array}{c}\text { Manta } \\
\text { ID }\end{array}$ & Sex & $\begin{array}{l}\text { DW } \\
(\mathrm{m})\end{array}$ & $\begin{array}{c}\text { Date } \\
\text { deployed }\end{array}$ & $\begin{array}{c}\text { Last I } \\
\text { detec- } \\
\text { tion }\end{array}$ & $\begin{array}{c}\text { Location } \\
\text { of last } \\
\text { detec- } \\
\text { tion }\end{array}$ & $\begin{array}{l}\text { No. of } \\
\text { days } \\
\text { detec- } \\
\text { table }\end{array}$ & $\begin{array}{l}\text { No. of } \\
\text { detec- } \\
\text { tions } \\
\text { at LEI }\end{array}$ & $\begin{array}{l}\text { No. of } \\
\text { days } \\
\text { detected } \\
\text { at LEI }\end{array}$ & $\begin{array}{l}\text { Resi- } \\
\text { dency } \\
\text { Index }\end{array}$ & $\begin{array}{c}\text { First photo-ID } \\
\text { observation } \\
\text { after last } \\
\text { detection }\end{array}$ \\
\hline 14676 & V16-6H 240s & 42 & F & 3.5 & 09/06/2009 & 09/12/2009 & 9 LEI & 183 & 2181 & 40 & $22 \%$ & 20/06/2011 \\
\hline 14679 & V16-6H 240s & 224 & F & 4 & 09/06/2009 & 17/09/2009 & 9 LEI & 100 & 580 & 20 & $20 \%$ & $10 / 10 / 2010$ \\
\hline 54724 & V16-6H 240s & 234 & M & 2.5 & 10/06/2009 & $24 / 01 / 2010$ & $0 \quad \mathrm{NSI}$ & 228 & 438 & 5 & $2 \%$ & \\
\hline 54720 & V16-6H 240s & 235 & $\mathrm{~F}$ & 4 & 10/06/2009 & 06/04/2010 & 0 LEI & $243^{\mathrm{a}}$ & 295 & 11 & $5 \%$ & $15 / 09 / 2010$ \\
\hline 54721 & V16-6H 240s & 169 & F & 4 & $12 / 06 / 2009$ & 08/02/2010 & 0 LEI & 241 & 7229 & 116 & $48 \%$ & $20 / 06 / 2011$ \\
\hline 54722 & V16-6H 240s & 247 & F & 2.8 & 12/06/2009 & 28/06/2009 & 9 LEI & 16 & 122 & 3 & $19 \%$ & $21 / 02 / 2011$ \\
\hline 14675 & V16-6H 240s & 251 & M & $2.5-3$ & 12/06/2009 & $31 / 01 / 2010$ & 0 LEI & 233 & 58 & 4 & $2 \%$ & $02 / 07 / 2010$ \\
\hline 14677 & V16-6H 240s & 223 & $\mathrm{~F}$ & 3.5 & 13/06/2009 & 23/11/2009 & 9 NSI & 164 & 92 & 6 & $4 \%$ & 01/03/2010 \\
\hline 14680 & V16-6H 240s & 64 & F & 4 & 13/06/2009 & 07/01/2011 & 1 LEI & 576 & 2588 & 72 & $13 \%$ & \\
\hline 14678 & V16-6H 240s & 65 & $\mathrm{M}$ & 3.5 & 13/06/2009 & 04/09/2009 & 9 LEI & 83 & 131 & 5 & $6 \%$ & $21 / 06 / 2010$ \\
\hline 54723 & V16-6H 240s & 89 & $\mathrm{~F}$ & $3.5-4$ & $17 / 06 / 2009$ & $21 / 09 / 2010$ & 0 LEI & $329^{\mathrm{a}}$ & 6086 & 81 & $25 \%$ & \\
\hline 54725 & V16-6H 240s & $291^{b}$ & M & 3.5 & $17 / 06 / 2009$ & $14 / 12 / 2010$ & 0 LEI & $413^{\mathrm{a}}$ & 9630 & 143 & $35 \%$ & $20 / 06 / 2011$ \\
\hline 64939 & V16-1H 240s & 116 & M & 3.5 & $30 / 03 / 2010$ & $28 / 10 / 2010$ & 0 NSI & $80^{\mathrm{a}}$ & 29 & 4 & $5 \%$ & $21 / 12 / 2010$ \\
\hline 64940 & V16-1H 240s & 400 & M & 2.8 & $30 / 06 / 2010$ & $26 / 10 / 2010$ & $0 \quad$ NSI & 118 & 228 & 12 & $10 \%$ & $28 / 06 / 2011$ \\
\hline 64937 & V16-1H 240s & 394 & M & 3.3 & $30 / 06 / 2010$ & $20 / 10 / 2010$ & 0 LEI & 112 & 287 & 13 & $12 \%$ & $20 / 06 / 2012$ \\
\hline 32689 & V16-5H 90s & 38 & $\mathrm{~F}$ & 3.7 & $21 / 02 / 2011$ & 15/05/2011 & $1 \mathrm{HI}$ & 83 & 742 & 8 & $10 \%$ & $22 / 10 / 2011$ \\
\hline 32688 & V16-5H 90s & 174 & F & 4 & $21 / 02 / 2011$ & 09/07/2011 & 1 LEI & 138 & 5071 & 38 & $28 \%$ & $10 / 07 / 2011$ \\
\hline 32691 & V16-5H 90s & 331 & F & 3.7 & $21 / 02 / 2011$ & 26/06/2011 & 1 LEI & 125 & 1840 & 15 & $12 \%$ & $14 / 09 / 2011$ \\
\hline 32687 & V16-5H 90s & 134 & M & 3.5 & $20 / 06 / 2011$ & $27 / 11 / 2011$ & 1 LEI & 160 & 7070 & 92 & $58 \%$ & $20 / 06 / 2012$ \\
\hline 32690 & V16-5H 90s & $291^{\mathrm{b}}$ & M & 3.5 & $20 / 06 / 2011$ & 04/09/2011 & 1 LEI & 76 & 535 & 8 & $11 \%$ & \\
\hline 32693 & V16-5H 90s & 361 & $\mathrm{~F}$ & 3.3 & $20 / 06 / 2011$ & $12 / 09 / 2011$ & $1 \mathrm{HI}$ & 84 & 180 & 5 & $6 \%$ & 18/06/2012 \\
\hline 32696 & V16-5H 90s & 545 & F & 3.5 & $20 / 06 / 2011$ & $21 / 08 / 2011$ & 1 LEI & 62 & 304 & 10 & $16 \%$ & \\
\hline 32694 & V16-5H 90s & 188 & $\mathrm{~F}$ & 3.3 & $20 / 06 / 2011$ & $06 / 12 / 2011$ & 1 NSI & 169 & 642 & 16 & $9 \%$ & 26/02/2012 \\
\hline 32692 & V16-5H 90s & 548 & M & 3.5 & $21 / 06 / 2011$ & $22 / 09 / 2011$ & 1 LEI & 93 & 802 & 8 & $9 \%$ & \\
\hline 32695 & V16-5H 90s & 549 & M & 3.5 & $21 / 06 / 2011$ & 13/12/2011 & $1 \mathrm{HI}$ & 175 & 20 & 3 & $2 \%$ & \\
\hline 32254 & V16-5H 90s & 91 & M & 3.5 & $21 / 06 / 2011$ & 19/01/2012 & 2 LEI & 212 & 1242 & 19 & $9 \%$ & 29/06/2012 \\
\hline 32258 & V16-5H 90s & 256 & $\mathrm{~F}$ & 4 & $21 / 06 / 2011$ & $24 / 10 / 2011$ & 1 NSI & 125 & 4323 & 58 & $46 \%$ & $20 / 06 / 2012$ \\
\hline 32256 & V16-5H 90s & 257 & F & $3.5-4$ & $21 / 06 / 2011$ & $13 / 11 / 2011$ & 1 NSI & 145 & 865 & 13 & $9 \%$ & \\
\hline 31001 & V16-5H 90s & 345 & F & 4.5 & 19/06/2012 & 28/08/2012 & 2 LEI & 70 & 639 & 7 & $10 \%$ & \\
\hline 30999 & V16-5H 90s & 685 & F & $3.5-4$ & $22 / 06 / 2012$ & $26 / 08 / 2012$ & 2 LEI & 65 & 143 & 4 & $6 \%$ & \\
\hline 31000 & V16-5H 90s & 35 & $\mathrm{~F}$ & 4.5 & $22 / 06 / 2012$ & $24 / 08 / 2012$ & 2 LEI & 63 & 906 & 12 & $19 \%$ & \\
\hline 31002 & V16-5H 90s & 165 & F & 3.7 & $22 / 06 / 2012$ & $27 / 08 / 2012$ & 2 LEI & 66 & 291 & 5 & $8 \%$ & \\
\hline 31005 & V16-5H 90s & 524 & $\mathrm{~F}$ & 4 & $22 / 06 / 2012$ & $25 / 08 / 2012$ & 2 LEI & 64 & 190 & 6 & $9 \%$ & \\
\hline 31006 & V16-5H 90s & 238 & F & 4 & $22 / 06 / 2012$ & $23 / 08 / 2012$ & 2 LEI & 62 & 607 & 9 & $15 \%$ & \\
\hline
\end{tabular}

\section{Range testing and detection performance}

Range tests and detection performance were conducted once for 5 receivers (not including Groupers Grovel) using a fixed-delay coded transmitter (V16$1 \mathrm{H}$ coded tag, operating at a frequency of $69 \mathrm{kHz}$, 10 s delay). The transmitter was attached to the stern of a boat and submerged $1 \mathrm{~m}$ below the surface. The vessel was then driven at low speed (1 to 2 knots) in constant direction for up to $1 \mathrm{~km}$ away from the receiver. Four transects were made for each receiver using the cardinal compass points as direction of motion. Precise boat location, using GPS coordinates, was recorded every $10 \mathrm{~s}$ to be matched with the detection data recorded by the receivers. Maximum detection ranges were plotted in Google Earth 6.1.0.5001 (Google) based on the GPS location recorded when a tag was detected by a receiver (Fig. 1a). The maximum detection range of all receivers was restricted by the elevated reef bathymetry of the coral cay and each receiver had a detection range of 200 to $800 \mathrm{~m}$ when not constrained by the coral reef structure (Fig. 1a). Since manta rays are seldom seen swimming in the inner reef area, the constraining 
effect of the reef on the detection range is unlikely to have severely affected our results. The Lighthouse Bommie receiver had an overlapping detection range with both the Severance and Sunset Drift receivers, and the Spiders Ledge receiver had an overlapping detection range with the Severance receiver, while the coverage of the Tubes receiver did not overlap with any of the others.

One transmitter deployed on individual 174 was detected continuously by the Severance receiver from 10 July 2011 until 29 August 2012. We considered that the individual had lost its tag within $300 \mathrm{~m}$ of the Severance receiver as it was not detected by any other nearby receivers after the 10 July 2011. The end of the 'detectable period' for that particular individual (ID 174) was set to the last 2 pings recorded by the Sunset Drift receiver (see Fig. 1a) on 9 July 2011 prior to it being detected continuously at Severance. After the 'detectable period', detection data from this lost tag was effectively used as a 'sentinel tag' to further assess the effect of environmental variables on the detection performance of the receiver. Although we did not know the exact distance the tag was located from the receiver, integrating this information in our models provided a better idea of the reliability of our manta ray presence data.

\section{Data analysis}

\section{Data processing}

The number of detections for each tag were grouped into hourly bins from June 2009 until September 2012. A solo detection (or hit) of any particular tag within a $1 \mathrm{~h}$ period was treated as a false positive and was not included in the dataset (Heupel et al. 2005). Period of detection for each tagged ray (with unique manta ID \& tag ID) was assessed from the date the individual was tagged until the date of its last detection at any receivers along the coast. Hourly presence and absence of manta ID during their respective periods of detection were added to the dataset. Data obtained during the servicing periods of the receivers, when 1 or more VR2W was not in the water, were not included in the final dataset used for the models to ensure that there was comparable effort during the study period. Periods of 'emigration' were removed from the dataset for each individual to reduce the excess of zeros. An individual tagged manta ray was considered to have emigrated from the study area if it was not detected for $5 \mathrm{~d}$ in a row after its last detection until $5 \mathrm{~d}$ prior to its next detection. Finally, data used for the models only comprised pooled detections from receivers located on the western side of LEI (Sunset Drift, Lighthouse Bommie and Severance, Fig. 1a) where manta rays are most commonly observed. Effects of candidate environmental variables on manta ray presence at this side of the island are assumed to be consistent. The final dataset consisted of 51461 presence and absence records, with 4367 indicating detections of tagged manta rays.

Habitat use

The total number of detections per receiver was determined to investigate the spatial use of LEI coral reef by reef manta rays. The number of detections was separated into 2 periods, June 2009 to February 2010, during which only 5 receivers were deployed (excludes Groupers Grovel; see Fig. 3), and June 2010 to September 2012, during which 6 receivers were deployed (includes Groupers Grovel).
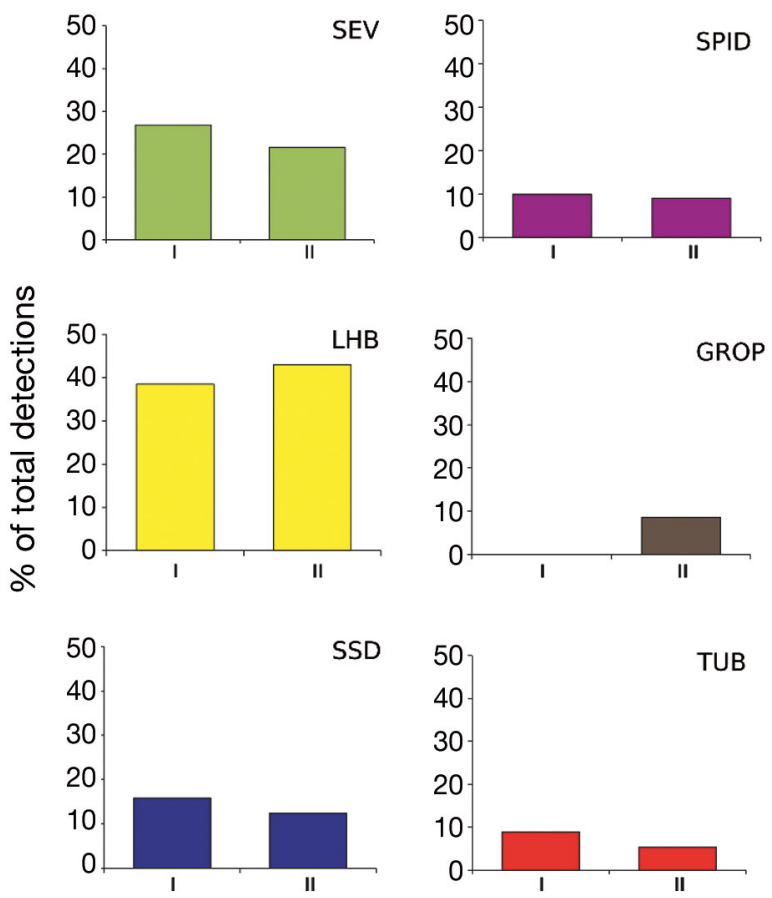

Fig. 3. Plots showing the percentage of total detections for each receiver between (I) June 2009 and February 2010 and (II) June 2010 and September 2012. No receivers were deployed during June 2009 and February 2010 at Groupers Grovel. SEV: Severance, LHB: Lighthouse Bommie, SSD: Sunset Drift, SPID: Spider's Ledge, GROP: Groupers Grovel, TUB: Tubes 


\section{Residency assessment}

Residency patterns were examined overall and in relation to detectability. Residency of a reef manta ray at LEI was assessed daily, with each residency day established when 2 or more detections of the same tag were recorded by any of the receivers within a $24 \mathrm{~h}$ period (00:00 to 23:59 h). Visualisation of residency histories was plotted by day for all individuals tagged throughout the study. The total number of days for which an individual ray was 'detectable' was calculated as the difference between the first and last detection of each tag recorded by any receiver available along the east coast of Australia.

Due to variation in the time an acoustic tag remained attached to the manta rays, an adjusted residency index was calculated for each individual. This was defined as the percentage of total number of days the individual was detected at LEI divided by the total period the individual's tag was detectable (Table 1). Continuous daily presence was defined as the total number of consecutive days an individual was detected around the island and was assessed by grouping all detections of individuals into daily bins.

\section{Generalised linear mixed models (GLMMs)}

GLMMs were used to examine the effect of environmental variables on the occurrence of reef manta rays at LEI (Table 2). GLMMs estimated the likeli- hood of the presence of reef manta rays in relation to a range of factors. This modelling approach incorporates fixed and random effects and handles nonnormal response distributions (Bolker et al. 2009). Calendar months and Manta ID were implemented as random factors, with Manta ID nested within Month (1/Month/Manta ID). This compensates for pseudoreplication that arises from repeated measures on the same individuals, and takes into consideration the potential bias in detection probability caused by the timing of tagging campaigns (mostly in winter), which leads to non-independence of errors. All other explanatory variables were coded as fixed factors. Continuous variables were fitted with a natural polynomial spline. Number of internal knots were determined from a visual examination of a fitted generalised additive mixed model (GAMM) that included all possible fixed and random effects but not their interactions. GLMMs were implemented using the glmer function and using the restricted maximum likelihood estimation in the lme4 package (Bates et al. 2015) in R v3.4.2 (R Core Team 2017). We report values for the Laplace approximation (nAGQ = 1). The presence or absence of each individual was assessed hourly and analysed as a binomial response (presence $=1$, absence $=0$ ) with a logit link function and binomial error structure. We used the dredge function from the MuMIn package (Barton 2017) to explore all combinations of explanatory variables from full models. Model simplification compared the full model (with all variables and interactions) with reduced models based on Akaike's information crite-

Table 2. Summary of variables used in the GLMM analyses

\begin{tabular}{|c|c|c|c|}
\hline Predictor & Type & Description & Values/units \\
\hline Manta ID & Random & Identifies manta ray individuals & Tag ID code \\
\hline Month & Random & Calendar month & 1-12 (January-December) \\
\hline Diel phase & Fixed-categorical & Diel phase & Sunrise, day, sunset, night \\
\hline Moon & $\begin{array}{l}\text { Fixed-continuous fitted } \\
\text { with natural spline }(\mathrm{df}=4) \\
\text { Range between } 0 \text { and } 1\end{array}$ & $\begin{array}{l}\text { Fraction of moon's disk } \\
\text { illuminated by the sun }\end{array}$ & \\
\hline Tidal phase & Fixed-categorical & Tidal phase & Low, flood, high, ebb \\
\hline Sea temperature & $\begin{array}{l}\text { Fixed-continuous fitted } \\
\text { with natural spline }(\mathrm{df}=4)\end{array}$ & Hourly sea temperature & Degrees Celsius \\
\hline Wind speed & $\begin{array}{l}\text { Fixed-continuous fitted with } \\
\text { natural spline }(\mathrm{df}=4)\end{array}$ & Hourly wind speed & Knots $(0-40+$ knots $)$ \\
\hline Wind direction & Fixed-categorical & Hourly wind direction & $\begin{array}{l}\text { North }\left(316^{\circ}-360^{\circ}, 0^{\circ}-45^{\circ}\right) \text {, } \\
\text { East }\left(46^{\circ}-135^{\circ}\right) \text {, South } \\
\left(136^{\circ}-225^{\circ}\right) \text {, West }\left(226^{\circ}-315^{\circ}\right)\end{array}$ \\
\hline Sentinel tag & $\begin{array}{l}\text { Fixed-continuous fitted with } \\
\text { natural spline }(\mathrm{df}=4)\end{array}$ & Hourly detection count & $\begin{array}{l}\text { Hit number of the sentinel } \\
\text { acoustic tag at Severance } \\
\text { receiver }\end{array}$ \\
\hline Sex & Fixed-categorical & Sex of individuals & Female, male \\
\hline
\end{tabular}


rion corrected for small sample size (AICc) to assess model support, where the smaller AICc values indicate better support for a model (Burnham \& Anderson 2004). The Bayesian information criterion (BIC) was also examined for comparison purposes of model selection across the different sets. The coefficient of determination $\left(\mathrm{R}^{2}\right)$ was obtained for the 5 models with highest support using the function sem.model. fits from the piecewiseSEM package in R (Lefcheck 2016). Interpretations were based on the combined evidence offered by all 3 sets of GLMMs. Best-fit models, selected using the AICc and $\mathrm{R}^{2}$ values and applying the principle of parsimony for model selection (Vandekerckhove et al. 2015), were then visually assessed for zero-inflation and over-dispersion from residuals diagnostic plots using the DHARMa package (Hartig 2017).

Graphical output of the best-fit GLMM was implemented in R using the sjp.glmer function in the sjPlot package v2.3.1 (Lüdecke 2017). This function provides a visual representation of relationships of the effects of predictors (environmental variables) on the response (presence of manta rays). The $y$-axis values are marginal probabilities of manta ray presence so that the range of the values displayed represents the importance of each predictor. Multicollinearity among predictors in full models excluding interactions was checked using variance inflation factors (VIF). Limited collinearity was assumed when VIF scores were $>4$ (Zuur et al. 2010)

\section{Explanatory variables}

The presence of elasmobranchs at particular sites is often sex-biased, and can highlight the role of particular habitats (e.g. pupping ground). The Sex of manta rays was thus added as a candidate predictor. Previous studies have shown that time of day influences the presence and activities of reef-associated elasmobranchs at particular sites (e.g. Dudgeon et al. 2013). The predictor Diel phase was included in our models and binned into 4 categories: sunrise, day, sunset and night. Times of sunrise and sunset for LEI were obtained from the Geoscience Australia website (www.ga.gov.au). Sunrise and sunset categories were defined as the time elapsing $1 \mathrm{~h}$ before and $1 \mathrm{~h}$ after the actual time of sunrise/sunset. Day and night were defined as the remaining time between sunrise and sunset. Wind-induced turbulence, affecting wave height and frequency, can influence the presence and activities of fishes in exposed areas, especially in shallow waters (e.g. Stoner 2004, Dudgeon et al. 2013). Wind data were included in our model as 2 separate variables: Wind speed was included as a continuous variable and Wind direction was binned into 4 categories: north, east, south and west (Table 2). Hourly wind data were obtained from the Australian Bureau of Metrology weather station located on LEI (station 039059, www.bom.gov.au/). The presence and activities of many reef elasmobranchs are often associated with tides at aggregation areas (Economakis \& Lobel 1998, O'Shea et al. 2010). Tide data were included in our models as Tidal phase, separated into 4 categories: low, flood, high and ebb tides. High and low tide categories were defined as the time elapsing $1 \mathrm{~h}$ before and $1 \mathrm{~h}$ after the peak tide. As lunar cycle and illumination can affect the activities of fish (Agenbag et al. 2003, Kitagawa et al. 2007), Moon illumination was included as a continuous variable using data obtained from the Naval Observatory Astronomical Application Department (aa.usno.navy.mil/). In addition, the interaction between Moon illumination and Tidal phase was added as a proxy to examine the effect of tidal intensity. The interaction between Moon illumination and Diel phase was integrated in the model to examine whether any effect of the moon was more likely related to illumination levels at night. The interaction Diel phase and Tidal phase was added to investigate whether tidal phase had more effect on reef manta ray presence at a specific time of the day (e.g. during daytime as observed by Jaine et al. 2012). Finally, the interaction between Diel phase and Sex was added to determine whether diel habitat use differs between males and females.

Sea temperature is considered one of the main drivers for fish movements (Agenbag et al. 2003, Kitagawa et al. 2007) and has been linked with seasonal aggregations of several reef-associated elasmobranchs (Dudgeon et al. 2013). A temperature logger (HOBO UA-004-64 v1.08, Onset Computer Corporation) was attached to the Lighthouse Bommie receiver at approximately $14 \mathrm{~m}$ depth (Fig. 1a) in October 2010 and programmed to record ambient temperature every $15 \mathrm{~min}$. Sea temperature data were averaged for each hour and included as a continuous variable.

Due to the challenges involved in the collection of environmental data, and to ensure the robustness of our results, 3 sets of GLMMs were run incorporating data from (1) the whole study period (2009 to 2012) with all environmental variables except Sea temperature, (2) a subset of data on detections from October 2010 onwards when sea temperature data were available, and (3) a subset of detection data from July 
2011 to integrate the hourly detection count of the Sentinel tag at the Severance receiver as a fixed effect (also including sea temperature) (see Tables 2 \& 3).

\section{RESULTS}

\section{Aggregation site occupation patterns}

The Lighthouse Bommie receiver recorded the highest proportion of detections, with approximately $39 \%$ of all detections for all receivers (Fig. 3). The pattern remained consistent when separating the frequency of detection into the 2 periods (Fig. 3). Over $77 \%$ of all the detections at LEI were recorded by receivers placed on the western side of the island. It is important to note that there was no assumption in our study that each receiver should have similar and constant detection ranges, and visitation patterns were analysed for waters surrounding LEI as estimated by the receivers' coverage.

\section{Residency, site fidelity and movements}

Tagged rays were mostly large individuals $(>2.5 \mathrm{~m})$, with disc-widths reaching estimated adult-size $(\sim 3 \mathrm{~m}$ for males and $\sim 3.5 \mathrm{~m}$ for females, see Couturier et al. 2014) (Table 1). All tagged reef manta rays revisited LEI at least once after being tagged and most individuals returned to the site on several occasions (Fig. 4). One individual was present at LEI on at least 143 days in a 413 d period, while another was present on 92 days over a $160 \mathrm{~d}$ period (Table 1).

The period of detectability of reef manta rays varied greatly among individuals, from 16 to $576 \mathrm{~d}$ with median of $121.5 \mathrm{~d}$ (Table 1). Tagged reef manta rays showed varying degrees of residency at LEI. The mean number of consecutive days individuals were present within the monitored acoustic range at LEI was $2.8 \pm 3$ (median =2). Although most individuals were present at LEI for only 1 day at a time, a maximum of 23 consecutive days was recorded for 1 female reef manta ray (Manta ID 89), while male

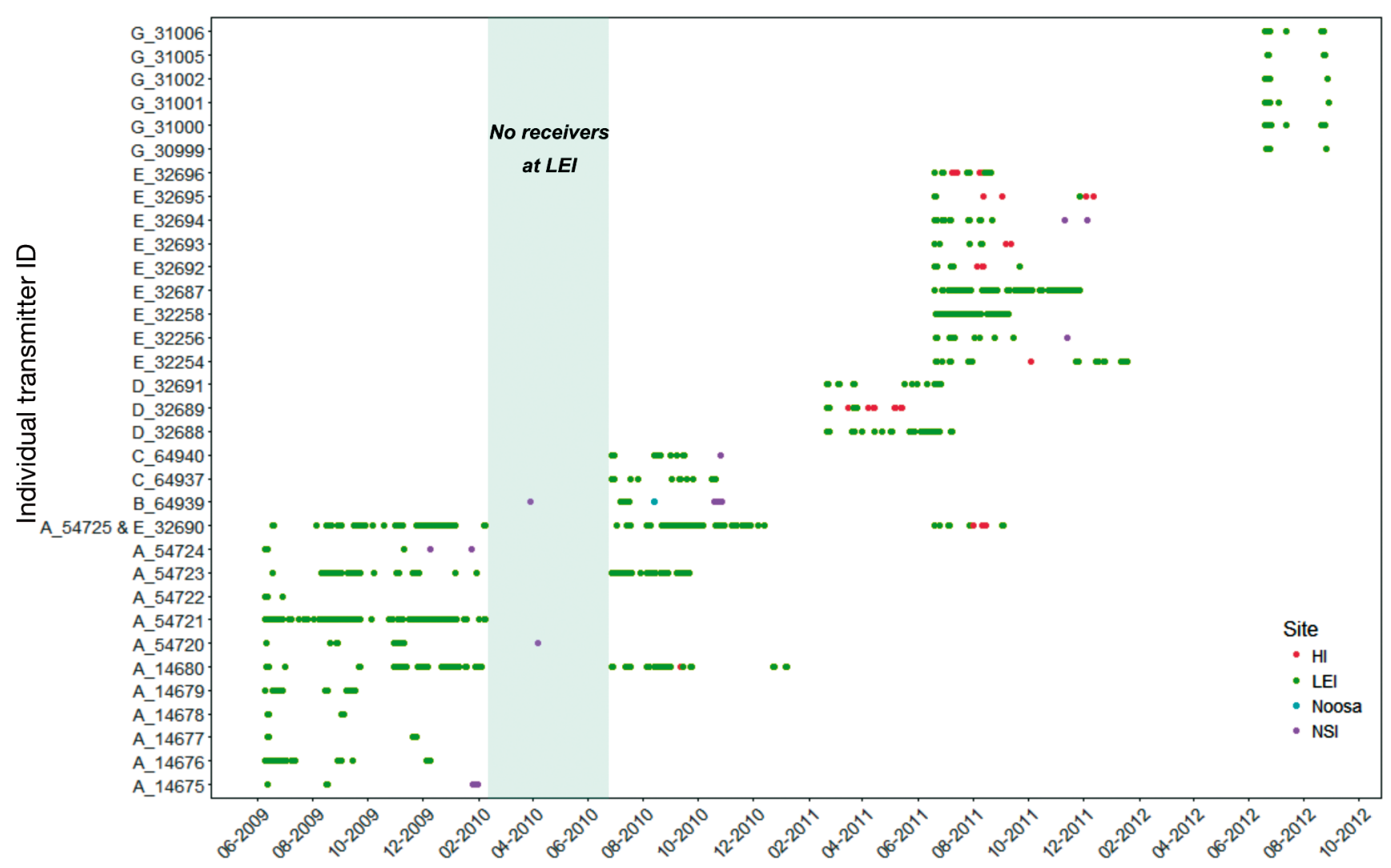

Fig. 4. Chronology of daily visitation patterns across all receivers deployed along the east coast of Australia (HI: Heron Island, LEI: Lady Elliot Island, Noosa: Noosa Heads, NSI: North Stradbroke Island, see Fig. 1c) for 33 tagged reef manta rays Mobula alfredi. Letters in front of the transmitter ID correspond to tagging campaign (A: June 2009, B: March 2010, C: June 2010, D: February 2011, E: June 2011, G: June 2012) 
reef manta rays were present between 1 and 14 consecutive days (Fig. 5).

Movements among several sites north and south of LEI were observed, with 15 tagged individuals detected at other monitored sites along the east Australian coastline (Fig. 4). Eight individuals (4 females, 4 males) travelled to the Heron Island aggregation site $(\sim 100 \mathrm{~km}$ northward) in both winter and summer, while 7 (3 females, 4 males) travelled to North Stradbroke Island ( 380 km southward) during summer (Figs. 1b \& 4). All were large individuals ( $>3 \mathrm{~m}$ disc width). At least 8 of the 15 individuals exhibited return movements to LEI during their respective detectable periods (Fig. 4). One individual displayed return movement to North Stradbroke Island and 3 to Heron Island (Fig. 4). Of these 15 travelling individuals, 11 were detected most often at LEI over their period of detectability (Fig. 4).

\section{Model results}

The 3 sets of GLMMs, i.e. (1) period 2009-2012 without Sea temperature, (2) period 2010-2012 with Sea temperature and (3) period 2011-2012 with Sentinel tag, showed consistent results regarding the variables that correlated with the presence and absence of manta rays off LEI (Table 3). Model selection varied according to $\mathrm{AIC}_{\mathrm{C}}$ or $\mathrm{BIC}$, with $\mathrm{BIC}$ ranking being more conservative and underpinning the weak effect of several predictors. Manta rays were significantly more likely to be detected during the

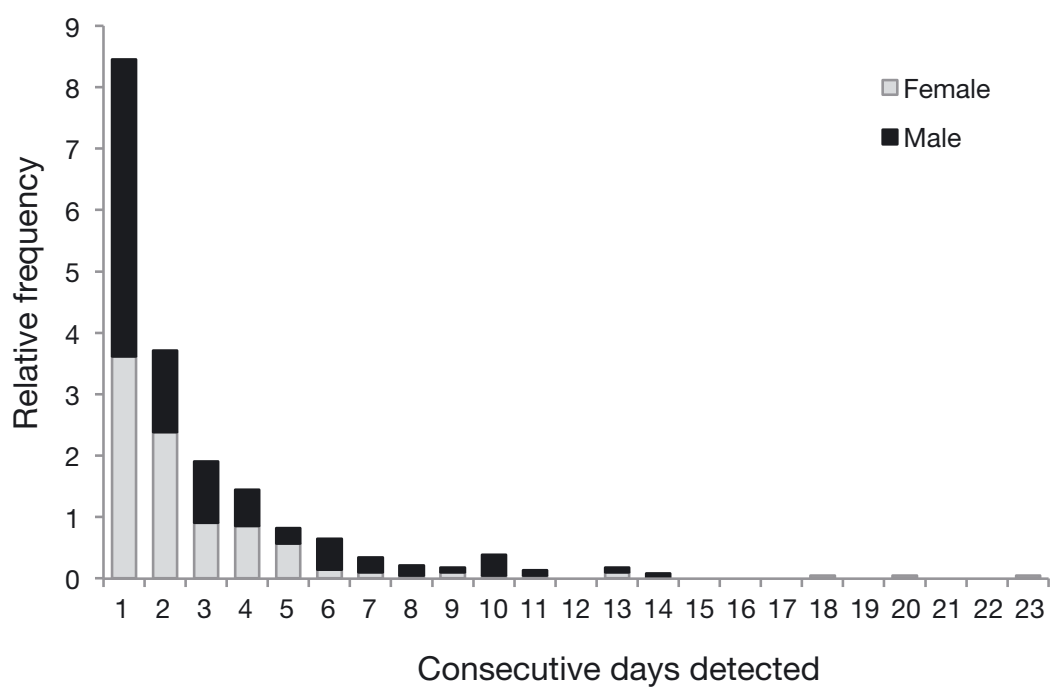

Fig. 5. Relative frequency distribution of the number of consecutive days female and male reef manta rays Mobula alfredi were present at Lady Elliot Island, pooled across 21 females and 12 males daytime than at night, with sunrise and sunset representing intermediate steps in the transition (Figs. 6 \& 7, Tables S2 \& S3 and Fig. S1 in the Supplement at www.int-res.com/articles/suppl/m599p125_supp.pdf). Time-of-day was consistently the strongest effect in all models. This was true even when accounting for potential changes in acoustic detectability (using the sentinel tag detection rate), which provides strong evidence that observed differences are a consequence of manta behaviour and not an artefact of variable levels of environmental noise (Figs. $6 \& 7$, Fig. S1).

Across the 2 sets of models where Sea temperature was included (Sets 2 and 3), manta rays were consistently more likely to be detected in cooler water (Fig. 7, Fig. S1). Similarly, all models suggest manta rays are less likely to be detected during periods with high moon illumination (Figs. 6 \& 7, Tables S2-S5 and Fig. S1 in the Supplement). Differences across the Moon illumination range were more pronounced with the GLMM Set 1 suggesting a small peak around the new moon. The effect of Tidal phase was generally weak (Figs. 6 \& 7, Tables S2-S5 and Fig. S1). Although having a weak effect, the 2-way interaction of Diel phase $\times$ Tidal phase is present in all GLMM sets and has a relatively consistent effect across the 3 model sets, with higher probability of manta ray detection during ebb and high tide at sunrise (Figs. $6 \&$ 7, Fig. S1).

Wind speed generally had a weak effect, with manta rays being more likely to be detected in calmer periods (Figs. 6 \& 7, Fig. S1). Results were more ambiguous in terms of Wind direction, but in general show marginally higher likelihood when the winds come from the north and lower likelihood during westerly winds (Fig. 6, Fig. S1). Twoway interactions (Moon illumination $\times$ Diel phase, Moon illumination $\times$ Tidal phase) were present in some final models but generally had weak effects and did not change the overall patterns of the main variables (Figs. $6 \& 7$, Fig. S1). Sex and the 2-way interaction Diel phase $\times$ Sex had a weak effect that was not consistent across model sets (Figs. $6 \&$ 7). Both Set 1 and 2 results suggest that females are more likely to be present than males during the daytime (Figs. 6 \& 7).

We present the graphical output for the best fit model of Set 1 (period 2009-2012 without Sea temperature) 


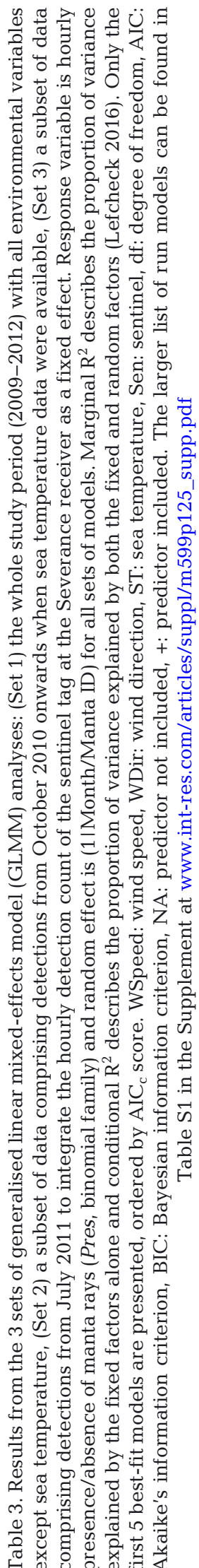

\begin{tabular}{|c|c|c|c|c|c|}
\hline$\sum_{4}^{0}$ & 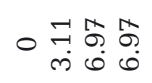 & $\bigcup_{4}^{U}$ & 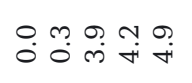 & $\sum_{4}^{u}$ & $\stackrel{m}{0} \stackrel{m}{\sim} \stackrel{0}{\rightarrow} \stackrel{\sim}{\sim}$ \\
\hline 这 & 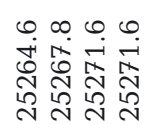 & U & 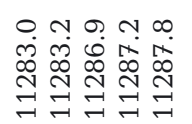 & 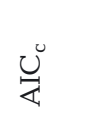 & 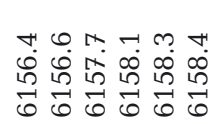 \\
\hline$\stackrel{\cup}{U^{\prime}}$ & 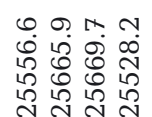 & $\stackrel{U}{\mathscr{m}}$ & 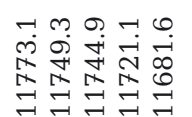 & $\stackrel{\circlearrowright}{\mathscr{n}}$ & 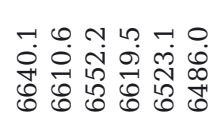 \\
\hline 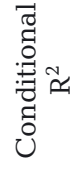 & 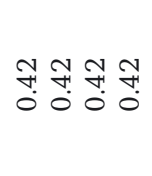 & 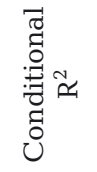 & 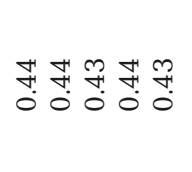 & 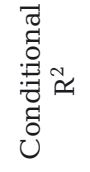 & 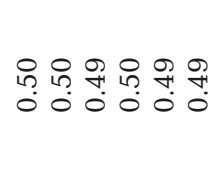 \\
\hline 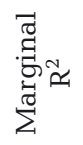 & 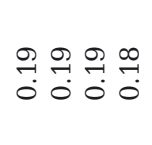 & 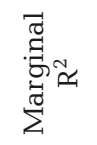 & 咅吉吉吉吉吉 & 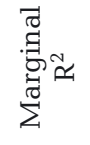 & 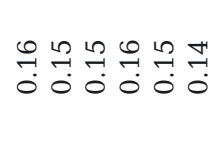 \\
\hline 㐘 & mid \& \& & 낭 & 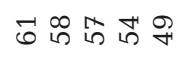 & 낭 & ชூ \\
\hline $\begin{array}{l}\dot{\Xi} \\
\dot{8} \\
\dot{z}\end{array}$ & $\overleftrightarrow{Z}+\overleftrightarrow{Z} \overleftrightarrow{Z}$ & 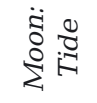 & $++++\overleftrightarrow{Z}$ & 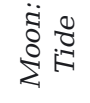 & 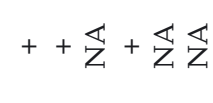 \\
\hline$\dot{\vec{\Xi}} \ddot{\Xi}$ & +++ & $\ddot{\vec{\varpi}} \ddot{\Xi}$ & +++++ & 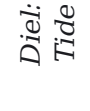 & $+++++\mathbb{Z}$ \\
\hline$\dot{\vec{\varpi}} \stackrel{凶}{\Delta}$ & ++ & $\begin{array}{l}\dot{\vec{\Phi}} 凶 \\
\ddot{\Delta}\end{array}$ & ++ 艺艺 + & 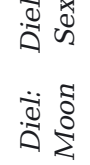 & $\begin{array}{l}+\overleftrightarrow{Z}+\overleftrightarrow{Z} \overleftrightarrow{Z}+ \\
++++++\end{array}$ \\
\hline $\begin{array}{l}\ddot{\ddot{\Phi}} \tilde{\delta} \\
\ddot{\Delta} \Sigma\end{array}$ & 艺艺 $+\overleftrightarrow{z}$ & $\stackrel{\square}{\square}$ & +++++ & $\stackrel{\tilde{E}}{3}$ & ++++++ \\
\hline$\stackrel{ت}{3}$ & ++++ & $\stackrel{3}{3}$ & $+\widetilde{z}+\widetilde{z}+$ & $\underset{\pi}{\pi}$ & ++++++ \\
\hline$\nexists_{i}^{*}$ & ++ & $\begin{array}{l}B \\
B \\
\infty \\
\omega\end{array}$ & $\begin{array}{l}+++++ \\
++\overleftrightarrow{z} \overleftrightarrow{z}+\end{array}$ & జ & $+\overleftrightarrow{Z}++\overleftrightarrow{Z}+$ \\
\hline 心 & ++ & ఫ్ల & $t+t+t$ & $\begin{array}{c}0 \\
w^{2} \\
3\end{array}$ & ++++++ \\
\hline 造 & $+++\overleftrightarrow{Z}$ & 3 & & ฐี & ++++++ \\
\hline & & is & +++++ & $\hat{n}$ & ++++++ \\
\hline$\stackrel{\Xi}{8}$ & + & $\frac{8}{\Sigma}$ & +++++ & $\frac{8}{\Sigma}$ & ++++++ \\
\hline $\bar{\Xi}$ & ++ & $\stackrel{\Xi}{\Xi}$ & +++++ & $\widetilde{\Xi}$ & ++++++ \\
\hline 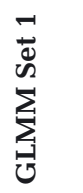 & 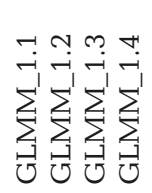 & $\sum_{\substack{j \\
0}}^{N}$ & 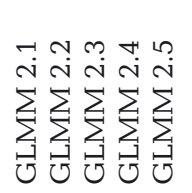 & $\sum_{j}^{\infty}$ & 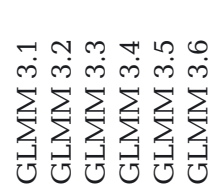 \\
\hline
\end{tabular}



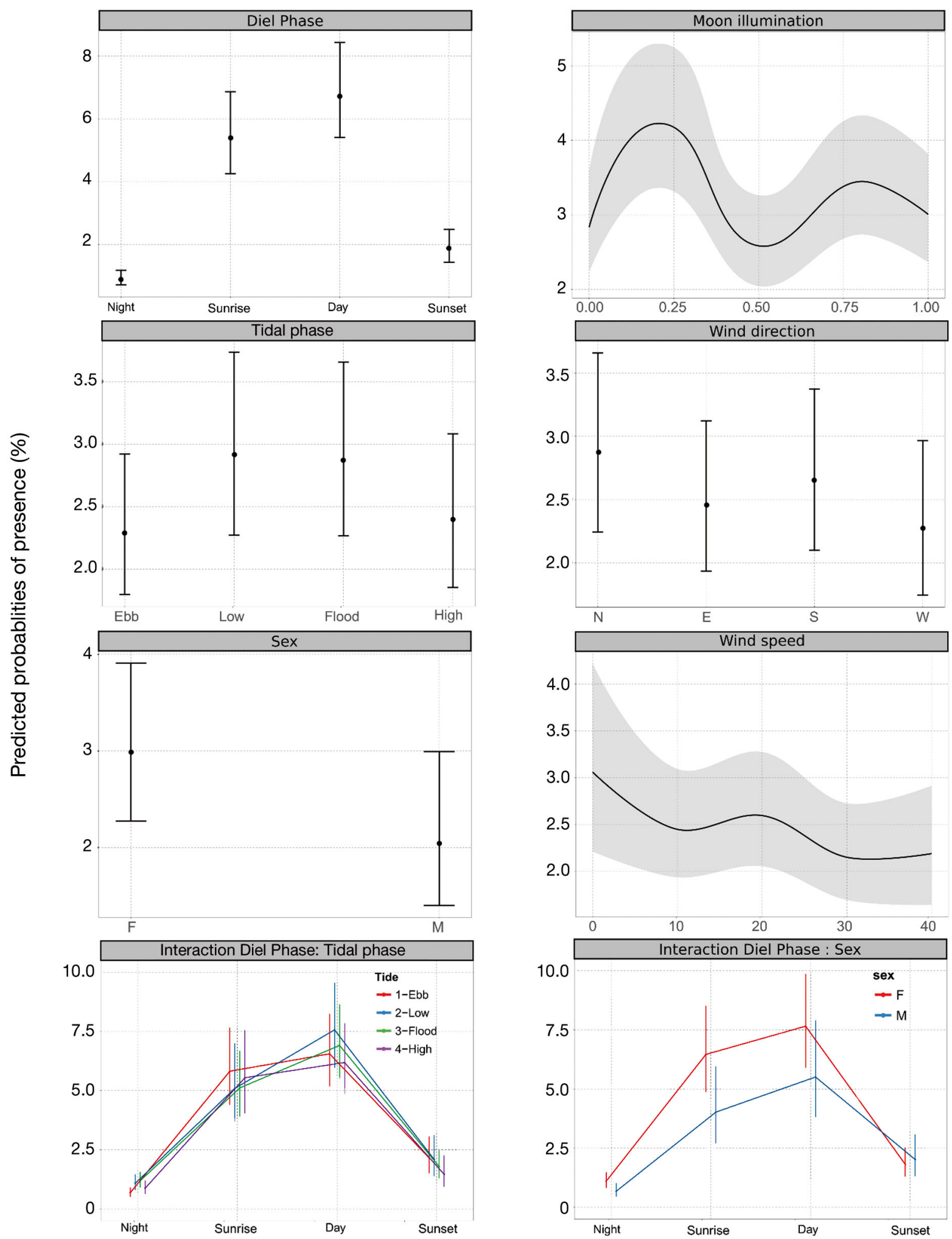

Fig. 6. Marginal effects of predictors on the presence of manta rays Mobula alfredi from the best-fit generalised linear mixed effects model for each environmental variable retained in GLMM Set 1 [Presence $\sim$ Diel phase $\times$ Sex + Diel phase $\times$ Tidal phase + ns(Moon illumination $)+$ WDir + ns $($ WSpeed $)+(1$ IMonth/Manta ID)]. Grey-shaded areas (in Moon illumination and Wind speed) and error bars represent the $95 \%$ confidence interval 

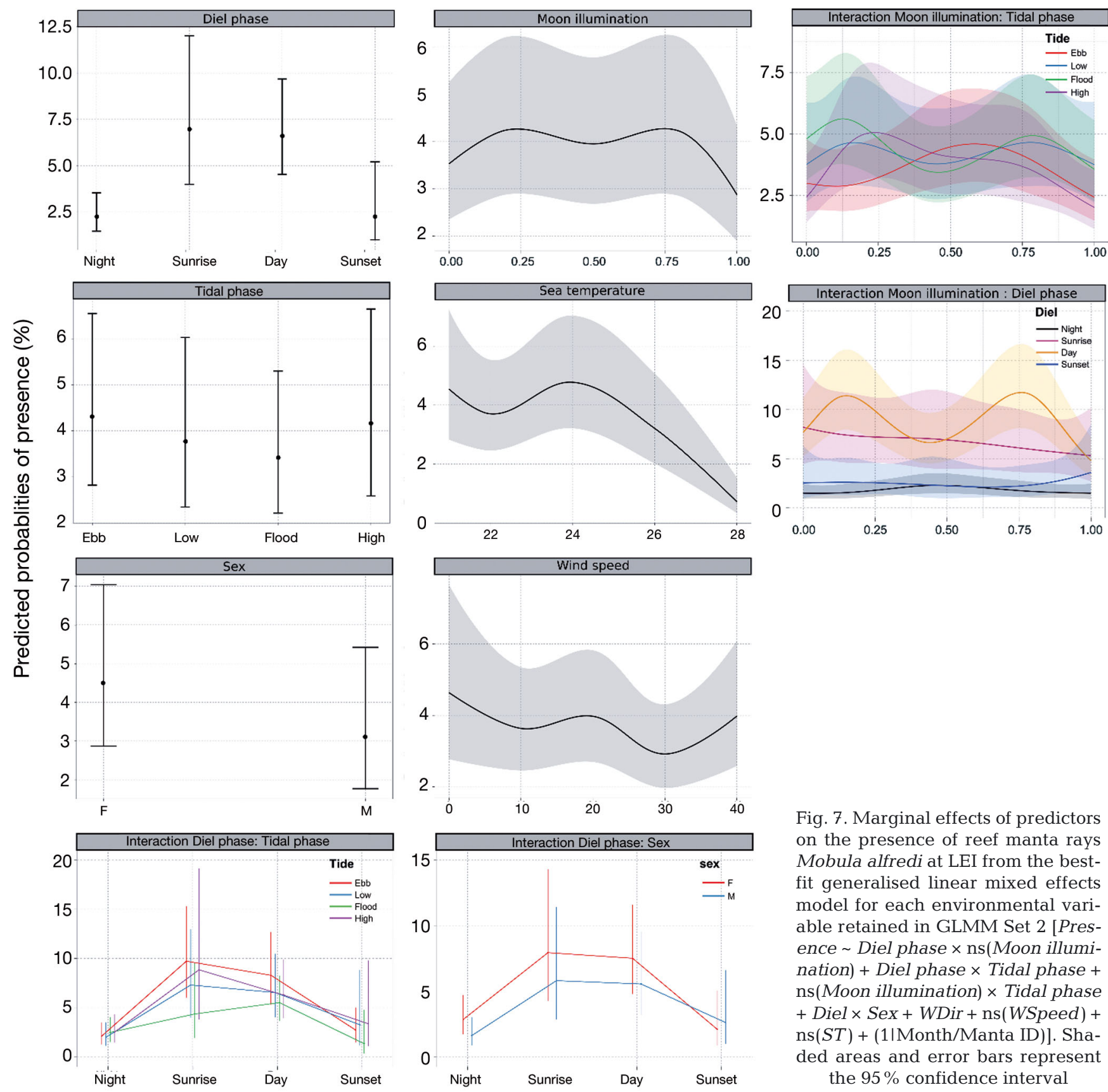

Fig. 7. Marginal effects of predictors on the presence of reef manta rays Mobula alfredi at LEI from the bestfit generalised linear mixed effects model for each environmental variable retained in GLMM Set 2 [Presence $\sim$ Diel phase $\times$ ns(Moon illumination) + Diel phase $\times$ Tidal phase + $\mathrm{ns}($ Moon illumination $) \times$ Tidal phase + Diel $\times$ Sex + WDir + ns $($ WSpeed $)+$ $\mathrm{ns}(S T)+(1 \mid$ Month/Manta ID)]. Shaded areas and error bars represent the $95 \%$ confidence interval

and Set 2 (period 2010-2012 with Sea temperature) in Figs. 6 \& 7. Graphical output of the best-fit model of Set 3 is available in Fig. S1 in the Supplement.

\section{DISCUSSION}

Passive acoustic telemetry enabled near continuous monitoring of reef manta ray activities in the vicinity of LEI, and provided new insights into the effects of different environmental variables on the occurrence of individuals at aggregation sites. Tagged individuals were mostly adults and all used this coral reef habitat repeatedly over several months. Although the effects of several environmental variables appeared to be relatively weak, we show that the presence of reef manta rays is higher during daytime and high and ebb tides, and lower during high moon illumination and during strong winds. This study provides a comprehensive quanti- 
tative analysis of the reef manta ray site fidelity, residency and visitation patterns at a key aggregation site in eastern Australia.

\section{Residency and site fidelity}

All tagged reef manta rays displayed site affinity to LEI, as all were detected at this site on multiple occasions within their recording periods. Some also displayed return movements to LEI after being detected at another site, and had the most detections at LEI. Couturier et al. (2014) showed that $>65 \%$ of the individuals previously identified using photo-identification techniques at LEI were re-sighted at that same site at least once. Our current study indicates that individuals using these waters can display considerable variability in residency and site fidelity. Three tagged reef manta rays spent $>40 \%$ of the recorded periods around the island and 1 individual was detected at the site for 23 consecutive days. Site fidelity in elasmobranchs is associated with a range of factors including foraging (Heupel \& Hueter 2002), reproduction (DiBattista et al. 2008), visiting cleaning stations (O'Shea et al. 2010), seeking shelter (Garla et al. 2006) and using sites as orientation landmarks (Klimley \& Nelson 1984). At LEI, reef manta rays are commonly seen engaged in feeding and/or cleaning activities (Jaine et al. 2012, Armstrong et al. 2016). They may also mate here as courtship behaviour and fresh mating scars have been observed, and both mature males and large females are seen year-round (Couturier et al. 2014). There is also likely to be some level of social organisation in this population and this may be related to their high site fidelity. This type of behaviour has been demonstrated in cat sharks Scyliorhinus canicula (Jacoby et al. 2010), lemon sharks Negaprion brevirostris (Guttridge et al. 2009) and blacktip reef sharks Carcharhinus melanopterus (Mourier et al. 2012), but has not yet been identified in reef manta rays.

Although several reef manta rays displayed site fidelity at LEI, there were still extended periods during which their presence was not recorded by any receivers (e.g. manta ID 42, 89, 91, 291). It is likely that these absences reflected emigration of individuals for days to months from the study area. Jaine et al. (2014) showed that satellite-tagged reef manta rays moved offshore from LEI to spend extended periods of time (up to $87 \%$ of a 3 mo period of tag deployment) off the southern Great Barrier Reef shelf where the Capricorn Eddy forms (Weeks et al. 2010). These absences are also consistent with documented movements of the species among aggregation sites along the east Australian coastline (Couturier et al. 2011, 2014). Transience was displayed by 9 individuals that only spent a limited time around LEI, were then detected by receivers deployed at other sites (i.e. North Stradbroke Island, Noosa Beach and Heron Island, Queensland) but did not return to LEI within their period of detectability. Our results provide further support to photo-ID records of movements as half of the acoustically tagged reef manta rays were detected at another site.

\section{Daily visitation patterns}

Reef manta rays exhibited strong diel visitation patterns at LEI, as they were more likely to be present during daytime than night-time. This result was consistent across all sets of models, even when accounting for temporal changes in the acoustic landscape. This demonstrates that diel variations in manta detection are likely to be a consequence of manta behaviour and not an artefact of the variable levels of noise often found in reef environments (Cagua et al. 2013). Reef manta rays generally arrived within detection range at sunrise, and then departed the area at sunset. This diurnal pattern in presence has also been found at reef manta ray aggregations in the Komodo National Park, Indonesia (Dewar et al. 2008), although it is unclear why reef manta rays return to shallow waters during the daytime. Similar visitation patterns were also observed in Hawai'i, where reef manta rays were more likely to be observed during daytime in shallow coastal waters and were often seen engaged in cleaning activities (Clark 2010). LEI may act as a landmark for reef manta rays to orientate themselves or to increase intra-specific encounters and social interactions (e.g. courtship, mating) during the day. Daytime habitat use at this site is also likely to be related to cleaning behaviours, commonly observed around LEI, as cleaner fishes are active only during the daytime and typically occupy relatively shallow water habitats (Lenke 1988, Côté 2000). Feeding behaviour near the surface is also regularly observed during the day at LEI (Jaine et al. 2012, Armstrong et al. 2016), suggesting individuals benefit from food sources available at the site, although near-surface zooplankton is not their only prey resource (Couturier et al. 2013). In addition, individuals may benefit from warmer shallow waters during the day to return and maintain their ectothermic body at favourable temperatures, after spending the night in deeper and cooler waters while (presumably) foraging. Evidence 
of behavioural thermoregulation has been found in other epipelagic elasmobranchs that forage at depth (e.g. Matern et al. 2000, Campana et al. 2011), including the whale shark Rhincodon typus, a giant planktivore that shares many life history traits with reef manta rays (Thums et al. 2013).

The diving behaviour of satellite-tagged reef manta rays in the Red Sea revealed that individuals tended to occupy shallow water $(<10 \mathrm{~m}$ depth) during the day and move to deeper adjacent waters at night (Braun et al. 2014). Similar nocturnal movement and diving activities in offshore and deeper waters have been observed for reef manta rays off Hawai'i using active acoustic telemetry (Clark 2010). Reef manta rays may thus move away from shallow areas to pelagic waters during the night to feed on larger zooplankton in the deep scattering layers and/or demersal zooplankton that undergo vertical diel migration to shallower depths at night (Alldredge \& King 1985, Robinson \& Goómez-Gutieérrez 1998, Clark 2010). A diurnal pattern of occupancy in inshore waters has also been observed for other elasmobranch species and nocturnal movements away from the studied areas have also been associated with foraging in the zebra shark Stegostoma fasciatum (Dudgeon et al. 2013), scalloped hammerhead shark Sphyrna lewini (Klimley et al. 1988), blacktip reef shark C. melanopterus (Heupel et al. 2005) and grey reef shark C. amblyrhynchos (Economakis \& Lobel 1998).

\section{Movement timing, effect of sea temperature}

Seasonality and sea temperature appear to be major drivers of reef manta ray occurrence at aggregation sites. Dewar et al. (2008) found that the occurrence of reef manta rays in the Komodo Marine Park, Indonesia, was linked to seasonal monsoonal shifts in the Indo-Pacific, which influence both sea temperature and productivity. The sea temperature at Komodo had an important effect on the individual visitation patterns. No individuals were detected in waters $>29^{\circ} \mathrm{C}$ in southern Komodo, whereas rays were present year-around at North Komodo where the water temperature remained $<29^{\circ} \mathrm{C}$. By contrast, Rohner et al. (2013) found that sightings of reef manta rays off Mozambique decreased in cooler waters $\left(18\right.$ to $21^{\circ} \mathrm{C}$ ) although there was no clear seasonal pattern.

The seasonal effect could not be tested directly in this study as we could not discriminate the effects of tagging campaign timing and seasonality in the population. Previous findings on reef manta ray occurrence at LEI using photo-identification (Couturier et al. 2011) and daily observations of reef manta ray presence (Jaine et al. 2012) showed an increase in manta ray abundance in winter. Jaine et al. (2012) suggested that greater occurrence of reef manta rays at LEI could be linked with local food availability as abundance was greater between 21 and $24^{\circ} \mathrm{C}$ and with increasing chlorophyll a concentration (used as a proxy for oceanic zooplankton abundance). The island is located near the continental shelf edge where the Capricorn Eddy typically forms. The associated upwelling of cool, nutrient-rich water leads to increased primary productivity (Bakun 2006, Weeks et al. 2010), and thus potentially increased zooplankton productivity in the region (Weeks et al. 2015). Similarly, a more frequent presence of individuals was also correlated with increased oceanic productivity at North Komodo during the monsoon season (Dewar et al. 2008), in Western Australia (Sleeman et al. 2007) and in the Maldives (Anderson et al. 2011). The similarity in strong seasonal patterns at different reef manta ray aggregation sites suggests that the abundance of reef manta rays at particular areas is closely related to the local food availability.

Sea temperature had an important effect in our study, with reef manta ray presence increasing with decreasing temperature. This suggests that water temperature is also an important driver underpinning the seasonal variation in occupation of LEI waters, and may influence reef manta ray activities. Sea temperature at LEI varies between 19 and $28^{\circ} \mathrm{C}$ over the year, which is likely to provide a suitable thermal habitat for the species based on other populations (Dewar et al. 2008, Rohner et al. 2013), and thus, may not have a direct effect on the visitation pattern. Instead, the effect of temperature on reef manta ray presence at this site may highlight a restriction in thermal and/or productive habitat availability along the coast during winter, which in turns triggers a peak aggregation at LEI. Individuals typically migrate southwards along the east Australian coastline during summer and aggregate at several locations where they are not usually sighted during winter (Couturier et al. 2011). In the present study, several individuals travelled to a southward aggregation site in summer (i.e. North Stradbroke Island), while others travelled northward without a clear temporal pattern to a coral cay island located in the Capricorn and Bunker group (i.e. Heron Island). All detected rays were adults and movement trajectories did not appear to be gender-related. These distinct movements may highlight difference in strategies adopted by individuals in response to the seasonal or geographic variation of food resources. 
Southward seasonal movements are assumed to relate to the East Australian Current flow that is stronger and brings warm water further southward during the austral summer (Church 1987, Roughan \& Middleton 2004). Increased shelf-edge upwelling and associated productivity (Bakun 1996), relating to greater East Australian Current intensity in summer, may allow individuals to exploit a larger range of suitable habitats along the coast, and may explain the lower prevalence of individuals at LEI in summer (Jaine et al. 2012). Colder temperature at southern sites during winter may thus trigger reef manta rays to move northward to find more suitable temperatures and/or productive habitat. By contrast, individuals remaining within the Capricorn and Bunker group region (i.e. LEI and Heron Island) in summer may forage on the resources associated with the Capricorn Eddy and/or other regional productivity events. More information on food resources availability over time in eastern Australia is needed to clearly associate these differences in movement with foraging strategy selection. Our limited sample size also hampers our ability to distinguish whether these movement are more likely to be related to the gender or maturity status of the individuals. The development of a more extensive acoustic array in eastern Australia that encompasses multiple reef manta ray aggregation sites would provide more detailed information on the visitation patterns and movements of individuals in relation to their environment at mesoand local scales.

\section{Tide and moon illumination}

Although effects of moon illumination on manta presence were weak, reef manta rays were less likely to be present during high moon illumination (around full moon). The interaction between tidal phase and moon illumination, which can be used as an indicator for tide intensity effect, had little or no effect on reef manta ray presence. This suggests that moon illumination, and not tidal current intensity, is the factor that influences the occurrence of reef manta rays. Similar to our results, reef manta rays in the Red Sea dived deeper on nights with increased moon illumination (Braun et al. 2014). The density and biomass of zooplankton emerging from the sediment around coral reefs can be higher in lower light conditions (Alldredge \& King 1980). This may explain the greater presence of reef manta rays around the island during the darker night-time conditions, as individuals may feed on the more abundant zooplankton resource available.

Tidal phase had a weak effect on reef manta ray presence at LEI and the main consistent pattern that was observed indicated that reef manta rays were more likely to be present during ebb and high tides at sunrise. Despite having little statistical power, this finding appears to fit with those of Armstrong et al. (2016), Jaine et al. (2012) and O'Shea et al. (2010). Armstrong et al. (2016) found an increase in both zooplankton biomass and reef manta ray feeding activities during ebb tides. Similarly, Jaine et al. (2012) showed that tides had a significant effect on the abundance of reef manta rays observed cleaning and foraging, with more individuals recorded at cleaning stations during the peak of the high tidal phase and feeding primarily during ebb tides. O'Shea et al. (2010) found that reef manta rays were more likely to be observed engaged in cleaning activities during ebb tides based on daytime remote video recording at Osprey Reef, Coral Sea. These studies suggest that tidal cycle has an effect on reef manta ray habitat use of LEI but not on their probability of presence. Our acoustic telemetry data cannot clearly discriminate between behaviours performed across each receiver site (e.g. cleaning vs. feeding vs. cruising), which could mask the importance of tidal cycle on the habitat use of reef manta rays at LEI. The differences in findings may also be linked to the inherent caveats associated with each study. Jaine et al. (2012) and Armstrong et al. (2016) relied on visual sightings during daylight hours with varying sampling effort across days and sites which may have biased results (e.g. cleaning behaviour was mostly observed during dives by Jaine et al. (2012), which mostly took place twice daily [ 2 to 3 $\mathrm{h} \mathrm{d}^{-1}$ ] and were restricted to a relatively small area). However, the relatively small sample size $(n=33)$ in the current study, combined with the limited study period considered in the models, may have limited the ability of the models to detect any significant effect of the tidal phase on reef manta ray occurrence patterns. Better understanding of the tidal cycle effect may be addressed by increasing the number of tagged individuals within the same period and further analysing occupation patterns at each receiver site around the island. Deployment of acoustic transmitters equipped with a pressure sensor on reef manta rays would also provide data on individual depth occupancy around each receiver. This information could then used as a proxy for common manta ray behaviours observed at LEI such as cleaning and feeding. 


\section{Wind direction and speed}

Westerly winds negatively affected the presence of reef manta rays at LEI. Comparison of the number of detections per receiver showed that reef manta rays tended to prefer the shallow ( 8 to $25 \mathrm{~m}$ depth) western side of the island. This is also the area where individuals are mostly sighted at cleaning stations and feeding near the surface around the island (Jaine et al. 2012, Armstrong et al. 2016). Reef manta rays might preferentially use the western side of the island as it is usually more sheltered from the prevailing south-easterly trade winds along the east coast of Australia. Exposure to westerly winds creates higher surge and wave activity on the usually sheltered side of the island that may disturb the feeding and cleaning activities of reef manta rays. The models also showed that reef manta rays were less likely to be present around LEI when winds exceeded 20 knots, presumably related to bigger seas in the waters adjacent to the island. Despite contrasting sampling methods, our results support the findings of Jaine et al. (2012), who found similar effects of wind speed and direction on reef manta ray abundance at this site. Zebra sharks in eastern Australia are also less likely to be present around their shallow aggregation site off North Stradbroke Island during bigger seas, as sub-surface surging water motion makes it difficult for individuals to rest on the sea bottom (Dudgeon et al. 2013). The actual reason(s) why reef manta rays seem to avoid rough surface waters is, however, unknown but could be linked to decreased visibility, decreased prey concentration through dispersal and/or increased predation risk. Alternatively, the lack of detections during strong wind/ weather events may be an artefact of the acoustic telemetry technology itself (see 'Caveats associated with acoustic telemetry' below).

\section{Caveats associated with acoustic telemetry}

Acoustic telemetry is a valuable tool for examining habitat use of a species, particularly for species that remain within the same area or species that return to the same location. Photo-ID studies have previously established that reef manta rays exhibit site affinity (Deakos et al. 2011, Couturier et al. 2014), which makes the species a good candidate for acoustic studies. There are, however, several constraints associated with the use of this technique (Heupel et al. 2005, Welsh et al. 2012, Dance et al. 2016). Acoustic studies are limited to areas where receivers are deployed, which may represent a relatively small proportion of the home range of the species. It is not possible to distinguish whether the non-detection of a tagged individual is due to (1) a large-scale movement away from the study area, (2) movement just beyond the detection range of the acoustic array, or (3) tag failure or loss. Environmental noise in coral reefs, generated by organisms and bubbles in the water from breaking waves and strong currents, can limit the detection performance of receivers (Welsh et al. 2012, Cagua et al. 2013, Mathies et al. 2014).

The detection range of receivers may vary with water temperature, tidal current speed and season, and between day and night (Mathies et al. 2014). However, we were unable to explicitly test these effects as the current methods used to undertake comprehensive range testing are logistically challenging and extremely time consuming (e.g. Cagua et al. 2013). Nevertheless, we were able to successfully overcome this limitation by integrating sentinel tag data to examine whether detections of this tag was influenced by the environmental variables tested. The models showed a slight effect, suggesting that to some extent, the detection capacity of the receiver was affected by environmental variables. It is possible, however, to distinguish between the effect of environmental variables and reef manta ray absence. Field observations showed that the major areas used by reef manta rays around the island during daytime are located within 50 to $100 \mathrm{~m}$ of one of the receivers. In addition, data from all receivers on the western side of the island were pooled. With the close proximity of receiver stations, environmental conditions at the different receiver locations on that part of LEI are considered to be consistent across locations. Thus, variation in detection ranges among receivers was unlikely to affect our interpretation and it appears reasonable to presume that if no detections were recorded on any receivers, the individual was not present around the island, even if detection ranges were moderately reduced. Biofouling can also affect receiver performance (Heupel et al. 2008), but was not considered an issue in this study as all receivers were serviced and refurbished 3 times a year and any biofouling was removed. One reef manta ray was observed with a heavily fouled tag, yet detections from this transmitter were recorded by several receivers on the day it was sighted. Although biofouling may have attenuated the acoustic signal of the transmitter, it was not blocked.

A major limitation in this study was tag retention. On average, transmitters were detectable for $5 \mathrm{mo}$, and several individuals were sighted that were missing their tags only 3 mo after deployment, which lim- 
ited interpretation of individual behaviours and longterm visitation patterns. There is a need for more testing to examine optimum tag deployment on marine species in general, and reef manta rays in particular. Testing should consider the body shape of the species and consider anchor types, length and towing tether material, as well as hydrodynamics of the externally deployed set up.

\section{Broader implications}

LEI adjacent waters are a key daytime aggregation site for a large part of the reef manta ray population in eastern Australia (Couturier et al. 2014). Despite low probabilities of hourly reef manta ray presence, the strong site fidelity and long residency periods displayed by several individuals in this study highlight the importance of LEI as a critical habitat for reef manta rays in eastern Australia. Our observation that reef manta rays generally leave the island at night, in conjunction with evidence that reef manta rays at the island derive much of their food from deeper zooplankton and that the shelf edge region of the Capricorn Eddy area is highly productive (Weeks et al. 2015), strongly suggest that LEI habitat is paired with an important offshore feeding site. Reef manta rays may use LEI during daytime for cleaning and social activities and move offshore at night-time to feed in productive waters. Opportunistic feeding still occurs during daytime at LEI when a certain threshold of zooplankton biomass is reached (Armstrong et al. 2016), but reef manta rays leave the island nightly, presumably to feed on high densities of large zooplankton such as euphausiids, which swarm in shelf-edge regions and provide a nutritious food source for fish (Nicol 1984, Gibbons 1995, Rohner et al. 2017). Similar observations off Hawai'i and Komodo suggest that reef manta ray occupancy of shallow aggregation sites is linked to the occurrence of a larger feeding site in neighbouring offshore waters (Dewar et al. 2008, Clark 2010). The presence and high use of cleaning stations at these shallow aggregation sites also highlights the ecological importance of cleaning activities for reef manta rays. Dewar et al. (2008) and Clark (2010) also found that reef manta rays habitat use and visitation patterns at shallow inshore aggregation sites were influenced by other factors including time of year, tidal phase and moon illumination. This suggests that visitation and occupancy patterns at aggregation sites by different subpopulations of reef manta rays are influenced similarly by environmental parameters. It would be informative to conduct further studies at several aggregation sites within the same region (e.g. east Australia) to determine whether similar environmental variables do in fact influence the movements and residency of reef manta rays.

Reef manta rays represent an important ecotourism resource worldwide (O'Malley et al. 2013, WardPaige et al. 2013). As site fidelity appears to be reasonably strong at shallow coastal aggregation sites, it is important to ensure that ecotourism does not negatively impact the cleaning, mating and feeding behaviours of reef manta rays and that these habitats are relatively free from pollution and habitat degradation (e.g. coral reefs provide refuges for some demersal zooplankton). There were similarities in findings between our study and that of Jaine et al. (2012) (e.g. effect of time of year and wind on presence of reef manta rays) which provide validation of the data quality collected through long-term citizen-science logbook data. Such methods of data collection present an important low-cost monitoring solution to stakeholders with limited financial means (Dickinson et al. 2010). These types of data can identify critical habitats for reef manta rays and the potential effects of different anthropogenic activities on reef manta ray habitat use. This would in turn inform management measures for key aggregation sites. LEI is classified as a 'Green Zone' in the Great Barrier Reef Marine Park, a 'no take' area where fishing, collecting or anchoring are not permitted without permission. Considering site fidelity and residency pattern of reef manta rays at this site, the protection of LEI coral reef habitat is likely to directly benefit the reef manta ray population of eastern Australia. As individuals regularly revisit this site, the long-term protection plan of LEI likely benefits the reef manta ray population over several generations. It is hoped that increased knowledge of the patterns of occurrence of reef manta rays at key aggregation sites will assist in management decisions in relation to coastal and inshore waters that include these aggregations.

Acknowledgements. We thank K. Fiora, M. Romanovski, J. Griffiths, M. Ludgate, C. Garraway, R. Cheseldene-Culley, R. Jeffery, C. Ansell, A. Rakovsky, Earthwatch volunteers and many other colleagues and dive associates for their assistance with the deployment and maintenance of acoustic equipment, and for providing us with manta ray photographs and sighting information. We are grateful to M. Heupel, J. Werry and the IMOS Animal Tracking Facility for lending acoustic receivers and providing detection of our tagged animals across multiple regional arrays. IMOS is a national collaborative research infrastructure supported by the Australian Government through the National Collaborative Research Infrastructure Strategy and the Super Science 
Initiative. We thank F. Januchowski-Hartley, C. Dudgeon, C. Brown and A. Gutteridge for their comments on the data analysis and on the manuscript. We are grateful to the Editor and the anonymous reviewers for their valuable feedback on the manuscript. This study was part of Project Manta and supported by the Australian Research Council Linkage Grant (LP110100712), ARC Future Fellowship (FT099172), The University of Queensland, Earthwatch Australia, Sea World Research and Rescue Foundation, Integrated Marine Observing System and Australian Animal Tagging and Monitoring System, Redland City Council, SE QLD Catchments and Kaufmann Productions. Field work was supported by Lady Elliot Island Eco Resort, Manta Lodge and Scuba Centre, and was conducted under a Great Barrier Reef Marine Park permit (G09/29853.1), Moreton Bay Marine Park permit (QS2008/CVL1440a) and Ethics approval (SBMS/071/08/SEAWORLD). L.I.E.C. is supported by the 'Laboratoire d'Excellence' LabexMER (ANR-10-LABX-19).

\section{LITERATURE CITED}

Agenbag J, Richardson A, Demarcq H, Fréon P, Weeks S, Shillington F (2003) Estimating environmental preferences of South African pelagic fish species using catch size- and remote sensing data. Prog Oceanogr 59: $275-300$

Alava MNR, Dolumbalo ERZ, Yaptinchay AA, Trono RB (2002) Fishery and trade of whale sharks and manta rays in the Bohol Sea, Philippines. In: Fowler SL, Reed TM, Dipper FA (eds) Elasmobranch Biodiversity, Conservation and Management: Proceedings of the International Seminar and Workshop, Sabah, Malaysia, July 1997. Occasional Paper of the IUCN Species Survival Commission No. 25. IUCN, Gland, p 132-148

Alldredge AL, King JM (1980) Effects of moonlight on the vertical migration patterns of demersal zooplankton. J Exp Mar Biol Ecol 44:133-156

Alldredge A, King J (1985) The distance demersal zooplankton migrate above the benthos: implications for predation. Mar Biol 84:253-260

* Anderson RC, Adam MS, Goes JI (2011) From monsoons to mantas: seasonal distribution of Manta alfredi in the Maldives. Fish Oceanogr 20:104-113

*Armstrong AO, Armstrong AJ, Jaine FRA, Couturier LIE and others (2016) Prey density threshold and tidal influence on reef manta ray foraging at an aggregation site on the Great Barrier Reef. PLOS ONE 11:e0153393

Bakun A (1996) Patterns in the ocean: ocean processes and marine population dynamics. California Sea Grant College System, National Oceanic and Atmospheric Administration, in cooperation with Centro de Investigaciones Biologicas de Noroeste, La Paz, Baja California Sur, San Diego, California

Bakun A (2006) Fronts and eddies as key structures in the habitat of marine fish larvae: opportunity, adaptive response and competitive advantage. Sci Mar 70:105-122

Bansemer C, Bennett M (2011) Sex- and maturity-based differences in movement and migration patterns of grey nurse shark, Carcharias taurus, along the eastern coast of Australia. Mar Freshw Res 62:596-606

Barnett A, Abrantes KG, Seymour J, Fitzpatrick R (2012) Residency and spatial use by reef sharks of an isolated seamount and its implications for conservation. PLOS ONE 7:e36574
Barton K (2017) MuMIn: Multi-Model Inference. R Package version 1.40.0. https://cran.r-project.org/web/packages/ MuMIn/MuMIn.pdf

Bates D, Maechler M, Bolker B, Walker S (2015). Fitting linear mixed-effects models using lme4. J Stat Softw 67: $1-48$

Bolker BM, Brooks ME, Clark CJ, Geange SW, Poulsen JR, Stevens MHH, White JSS (2009) Generalized linear mixed models: a practical guide for ecology and evolution. Trends Ecol Evol 24:127-135

* Braun CD, Skomal GB, Thorrold SR, Berumen ML (2014) Diving behavior of the reef manta ray links coral reefs with adjacent deep pelagic habitats. PLOS ONE 9: e88170

* Bruce BD, Bradford RW (2013) The effects of shark cagediving operations on the behaviour and movements of white sharks, Carcharodon carcharias, at the Neptune Islands, South Australia. Mar Biol 160:889-907

* Burnham KP, Anderson DR (2004) Multimodel inference understanding AIC and BIC in model selection. Sociol Methods Res 33:261-304

* Cagua EF, Berumen ML, Tyler EHM (2013) Topography and biological noise determine acoustic detectability on coral reefs. Coral Reefs 32:1123-1134

Campana SE, Dorey A, Fowler M, Joyce W, Wang Z, Wright D, Yashayaev I (2011) Migration pathways, behavioural thermoregulation and overwintering grounds of blue sharks in the northwest Atlantic. PLOS ONE 6:e16854

Chapman DD, Pikitch EK, Babcock E, Shivji MS (2005) Marine reserve design and evaluation using automated acoustic telemetry: a case-study involving coral reefassociated sharks in the Mesoamerican Caribbean. Mar Technol Soc J 39:42-55

* Church JA (1987) East Australian Current adjacent to the Great Barrier Reef. Mar Freshw Res 38:671-683

Clark TB (2010) Abundance, home range, and movement patterns of manta rays (Manta alfredi, $M$. birostris) in Hawai'i. PhD thesis, University of Hawai'i, Manoa

Côté IM (2000) Evolution and ecology of cleaning symbioses in the sea. Oceanogr Mar Biol Annu Rev 38:311-355

* Couturier LIE, Jaine FRA, Townsend KA, Weeks SJ, Richardson AJ, Bennett MB (2011) Distribution, site affinity and regional movements of the manta ray, Manta alfredi (Krefft, 1868), along the east coast of Australia. Mar Freshw Res 62:628-637

* Couturier LIE, Rohner CA, Richardson AJ, Marshall AD and others (2013) Stable isotope and signature fatty acid analyses suggest reef manta rays feed on demersal zooplankton. PLOS ONE 8:e77152

\% Couturier LIE, Dudgeon CL, Pollock KH, Jaine FRA and others (2014) Population dynamics of the reef manta ray Manta alfredi in eastern Australia. Coral Reefs 33: 329-342

*Dance MA, Moulton DL, Furey NB, Rooker JR (2016) Does transmitter placement or species affect detection efficiency of tagged animals in biotelemetry research? Fish Res 183:80-85

* Deakos MH, Baker JD, Bejder L (2011) Characteristics of a manta ray Manta alfredi population off Maui, Hawaii, and implications for management. Mar Ecol Prog Ser 429:245-260

* Dewar H, Mous P, Domeier M, Muljadi A, Pet J, Whitty J (2008) Movements and site fidelity of the giant manta ray, Manta birostris, in the Komodo Marine Park, Indonesia. Mar Biol 155:121-133 
DiBattista JD, Feldheim KA, Thibert-Plante X, Gruber SH, Hendry AP (2008) A genetic assessment of polyandry and breeding-site fidelity in lemon sharks. Mol Ecol 17: 3337-3351

Dickinson JL, Zuckerberg B, Bonter DN (2010) Citizen science as an ecological research tool: challenges and benefits. Annu Rev Ecol Evol Syst 41:149-172

Dobson A, Lodge D, Alder J, Cumming GS and others (2006) Habitat loss, trophic collapse, and the decline of ecosystem services. Ecology 87:1915-1924

Dudgeon CL, Lanyon JM, Semmens JM (2013) Seasonality and site fidelity of the zebra shark, Stegostoma fasciatum, in southeast Queensland, Australia. Anim Behav 85: $471-481$

* Dulvy NK, Ellis JR, Goodwin NB, Grant A, Reynolds JD, Jennings $S$ (2004) Methods of assessing extinction risk in marine fishes. Fish Fish 5:255-276

Economakis AE, Lobel PS (1998) Aggregation behavior of the grey reef shark, Carcharhinus amblyrhynchos, at Johnston Atoll, Central Pacific Ocean. Environ Biol Fishes 51:129-139

* Garla RC, Chapman DD, Wetherbee BM, Shivji M (2006) Movement patterns of young Caribbean reef sharks, Carcharhinus perezi, at Fernando de Noronha Archipelago, Brazil: the potential of marine protected areas for conservation of a nursery ground. Mar Biol 149:189-199

* Gibbons MJ (1995) Observation of euphausiid assemblages of the south coast of South Africa. S Afr J Mar Sci 16: 141-148

Guttridge T, Gruber S, Gledhill K, Croft D, Sims D, Krause J (2009) Social preferences of juvenile lemon sharks, Negaprion brevirostris. Anim Behav 78:543-548

* Hartig F (2017). DHARMa: residual diagnostics for hierarchical (multi-level / mixed) regression models. R package version 0.1.5. https://cran.r-project.org/web/packages/ DHARMa/DHARMa.pdf

*Heupel M, Hueter R (2002) Importance of prey density in relation to the movement patterns of juvenile blacktip sharks (Carcharhinus limbatus) within a coastal nursery area. Mar Freshw Res 53:543-550

Heupel MR, Simpfendorfer C, Lowe C (2005) Passive acoustic telemetry technology: current applications and future directions. Results of the VR2 workshop held on Catalina Island, $28 \mathrm{Nov}$ to $1 \mathrm{Dec}, 2005$. Mote Technical Report, Mote Marine Laboratory, Sarasota, FL

Heupel MR, Carlson JK, Simpfendorfer CA (2007) Shark nursery areas: concepts, definition, characterization and assumptions. Mar Ecol Prog Ser 337:287-297

Heupel MR, Reiss KL, Yeiser BG, Simpfendorfer CA (2008) Effects of biofouling on performance of moored data logging acoustic receivers. Limnol Oceanogr Methods 6: 327-335

* Hueter RE, Heupel MR, Heist EJ, Keeney DB (2005) Evidence of philopatry in sharks and implications for the management of shark fisheries. J Northwest Atl Fish Sci 35:239-247

Jacoby DMP, Busawon DS, Sims DW (2010) Sex and social networking: the influence of male presence on social structure of female shark groups. Behav Ecol 21:808-818

* Jaine FRA, Couturier LIE, Weeks SJ, Townsend KA, Bennett MB, Fiora K, Richardson AJ (2012) When giants turn up: sighting trends, environmental influences and habitat use of the manta ray Manta alfredi at a coral reef. PLOS ONE 7:e46170

Jaine FRA, Rohner CA, Weeks SJ, Couturier LIE, Bennett
MB, Townsend KA, Richardson AJ (2014) Movements and habitat use of reef manta rays off eastern Australia: Offshore excursions, deep diving and eddy affinity revealed by satellite telemetry. Mar Ecol Prog Ser 510: 73-86

Jorgensen SJ, Chappel TK, Anderson S, Hoyos M, Reeb C, Block BA (2012) Connectivity among white shark coastal aggregation areas in the Northeastern Pacific. In: Domeier ML (ed) Global perspectives on the biology and life history of the white shark. CRC Press, Boca Raton, FL, p 159-168

Kitagawa T, Boustany AM, Farwell CJ, Williams TD, Castleton MR, Block BA (2007) Horizontal and vertical movements of juvenile bluefin tuna (Thunnus orientalis) in relation to seasons and oceanographic conditions in the eastern Pacific Ocean. Fish Oceanogr 16:409-421

KKlimley AP, Nelson DR (1984) Diel movement patterns of the scalloped hammerhead shark (Sphyrna lewini) in relation to El Bajo Espiritu Santo: a refuging central-position social system. Behav Ecol Sociobiol 15:45-54

*Klimley AP, Butler SB, Nelson DR, Stull AT (1988) Diel movements of scalloped hammerhead sharks, Sphyrna lewini Griffith and Smith, to and from a seamount in the Gulf of California. J Fish Biol 33:751-761

* Lefcheck JS (2016) piecewiseSEM: Piecewise structural equation modeling in $\mathrm{R}$ for ecology, evolution, and systematics. Methods Ecol Evol 7:573-579

* Lenke R (1988) Hormonal control of sleep-appetitive behaviour and diurnal activity rhythms in the cleaner wrasse Labroides dimidiatus (Labridae, Teleostei). Behav Brain Res 27:73-85

* Lüdecke D (2017) sjPlot: data visualization for statistics in social science. R package version 2.3.1. https://cran.rproject.org/web/packages/sjPlot/sjPlot.pdf

Marshall AD, Compagno LJV, Bennett MB (2009) Redescription of the genus Manta with resurrection of Manta alfredi (Krefft, 1868) (Chondrichthyes; Myliobatoidei; Mobulidae). Zootaxa 2301:1-28

* Marshall A, Kashiwagi T, Bennett MB, Deakos MH and others (2011) Manta alfredi. IUCN Red List of Threatened Species 2011: e.T195459A8969079

Matern SA, Cech JJ, Hopkins TE (2000) Diel movements bat rays, Myliobatis californica, in Tomales Bay, California: evidence for behavioral thermoregulation? Environ Biol Fishes 58:173-182

*Mathies N, Ogburn M, McFall G, Fangman S (2014) Environmental interference factors affecting detection range in acoustic telemetry studies using fixed receiver arrays. Mar Ecol Prog Ser 495:27-38

*Mourier J, Vercelloni J, Planes S (2012) Evidence of social communities in a spatially structured network of a freeranging shark species. Anim Behav 83:389-401

* Nicol S (1984) Population structure of daytime surface swarms of the euphausiid Meganyctiphanes norvegica in the Bay of Fundy. Mar Ecol Prog Ser 18:241-251

*'Malley MP, Lee-Brooks K, Medd HB (2013) The global economic impact of manta ray watching tourism. PLOS ONE 8:e65051

${ }^{*}$ 'Shea OR, Kingsford MJ, Seymour J (2010) Tide-related periodicity of manta rays and sharks to cleaning stations on a coral reef. Mar Freshw Res 61:65-73

$\mathrm{R}$ Core Team (2017) R: A language and environment for statistical computing. R Foundation for Statistical Computing, Vienna. https://www.R-project.org/

Robinson CJ, Goómez-Gutieérrez J (1998) Daily vertical 
migration of dense deep scattering layers related to the shelf-break area along the northwest coast of Baja California, Mexico. J Plankton Res 20:1679-1697

Rohner CA, Pierce SJ, Marshall AD, Weeks SJ, Bennett MB, Richardson AJ (2013) Trends in sightings and environmental influences on a coastal aggregation of manta rays and whale sharks. Mar Ecol Prog Ser 482:153-168

Rohner CA, Burgess KB, Rambahiniarison JM, Steward JD, Ponzo A, Richardson AJ (2017) Mobulid rays feed on euphausiids in the Bohol Sea. R Soc Open Sci 4:161060

Roughan M, Middleton JH (2004) On the East Australian Current: variability, encroachment, and upwelling. J Geophys Res 109:C07003

Rowat D, Brooks K, March A, McCarten C and others (2011) Long-term membership of whale sharks (Rhincodon typus) in coastal aggregations in Seychelles and Djibouti. Mar Freshw Res 62:621-627

Sleeman JC, Meekan MG, Wilson SG, Jenner CKS and others (2007) Biophysical correlates of relative abundances of marine megafauna at Ningaloo Reef, Western Australia. Mar Freshw Res 58:608-623

Stoner A (2004) Effects of environmental variables on fish feeding ecology: implications for the performance of baited fishing gear and stock assessment. J Fish Biol 65: 1445-1471

Thums M, Meekan M, Stevens J, Wilson S, Polovina J (2013) Evidence for behavioural thermoregulation by the world's largest fish. J R Soc Interface 10:20120477

Editorial responsibility: Scott Shaffer, San Jose, California, USA
Travis JMJ (2003) Climate change and habitat destruction: a deadly anthropogenic cocktail. Proc R Soc B 270: $467-473$

Vandekerckhove J, Matzke D, Wagenmakers EJ (2015). Model comparison and the principle of parsimony. In: Busemeyer JR, Wang Z, Townsend JT, Eidels A (eds) The Oxford handbook of computational and mathematical psychology. Oxford University Press, Oxford, p 300-319

*Venier L, Fahrig L (1996) Habitat availability causes the species abundance-distribution relationship. Oikos 76: 564-570

* Ward-Paige CA, Davis B, Worm B (2013) Global population trends and human use patterns of manta and mobula rays. PLOS ONE 8:e74835

*Weeks S, Bakun A, Steinberg C, Brinkman R, Hoegh-Guldberg O (2010) The Capricorn Eddy: a prominent driver of the ecology and future of the southern Great Barrier Reef. Coral Reefs 29:975-985

Weeks S, Magno-Canto M, Jaine F, Brodie J, Richardson A (2015) Unique sequence of events triggers manta ray feeding frenzy in the southern Great Barrier Reef, Australia. Remote Sens 7:3138-3152

Welsh J, Fox R, Webber D, Bellwood D (2012) Performance of remote acoustic receivers within a coral reef habitat: implications for array design. Coral Reefs 31:693-702

* Zuur AF, Ieno EN, Elphick CS (2010) A protocol for data exploration to avoid common statistical problems. Methods Ecol Evol 1:3-14

Submitted: June 23, 2017; Accepted: April 25, 2018

Proofs received from author(s): June 20, 2018 